\title{
ANALISE PRELIMINAR DO DESEMPENHO DE UM SISTEMA \\ DE MEDIDAS DE EVAPORAÇÃO PARA TANQUE CLASSE A
}

\section{MALAQUIAS DA SILVA AMORIM NETO}

Orientador: Dr. Nilson Augusto Villa Nova

Dissertação apresentada à Escola Superior de Agricultura "Luiz de Queiroz" da Universidade de São Paulo, para obtenção do título de Mestre em Agrometeorologia.

P I R A C I C A B A

Estado de São Paulo - Brasil

Novembro, 1981 
ii.

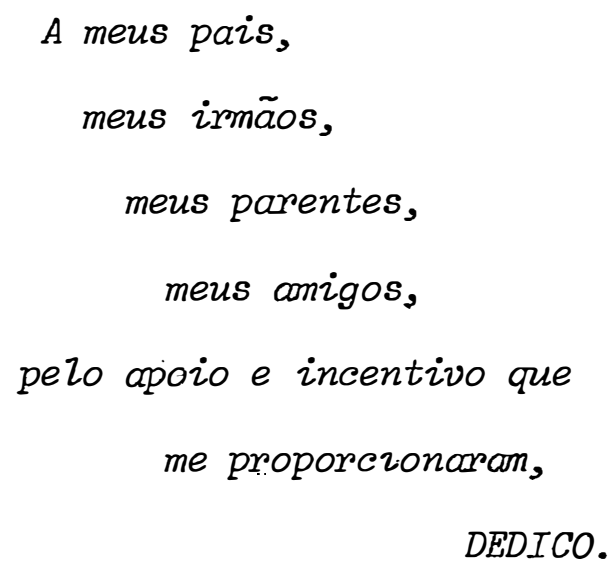

A minha noiva Railda, pélo carinho, apoio e incentivo, OFERECO. 
iii.

HOMENAGEM especial,

ao Prof. Dr. Nilson. Augusto Vilza Nova, o anigo sempre presente. 


\section{AGRADECIMENTOS}

Ao concluir este trabalho, a minha gratidão às seguin tes pessoas e instituições:

Ao Prof. Dr. Nilson Augusto Villa Nova, pelo apoio, orientação, estímulo e amizade, constantes em todos os momentos.

Ao Prof. Dr. Jesus Marden dos Santos, por ter me proporcionado a oportunidade de realizar este trabalho.

Aos Professores do Departamento de Física e Agrometeorologia e de ou tros Departamentos da ESALQ, pela contribuição à minha formação.

Ao Prof. Dr. Humberto de Campos, pela orientação nas anālises estatísticas dos resultados.

A Sra. Aurea B. Michelotto e à Srta. Ana Maria da Silva Maia, Secretārias do Departamento de Física e Meteorologia da ESALQ, pe1a amizade e atenção dispensadàs.

Ao Luiz Cláudio, Francisco e Paulo, funcionärios do Departamento de Física e Meteorologia, pela ajuda proporcionada na realização des te trabalho.

Aos demais funcionários do. Departamento de Física e Meteorologia.

Aos funcionärios da Biblioteca da ESALQ; pela atenção dispensada.

Aos funcionários da Seção de Pós-Graduação da ESALQ, pela dedicação e boa vontade em solucionar nossos problemas. 
A Srta. Sonia Maria Destefano Piedade, estagiāria do Departamento de Matemética e Estatística da ESALQ, pela contribuição na anālise dos dados.

Aos Engenheiros-Agrônomos Flávio Gilberto Herter e Paulo Henrique Caramori, pelo apoio e incentivo dentro e fora do curso.

Aos demais colegas do Curso de Pós-Graduação em Agrometeorologia.

A Maria Izalina Ferreira Alves, pela amizade e colaboração na ela boração do presente trabalho.

Ao CNPq - Conselho Nacional de Desenvolvimento Científico e Tecnológico, pela bolsa de estudos concedida para realização do Curso de Pós-Graduação em Agrometeorologia da ESALQ/USP.

A firma APAGER - Aparelhos de Precisão para Agricultura em Geral Ltda, pela fabricação do equipamento utilizado neste trabalho.

A todos aqueles cujos nomes não foram aqui citados, que de alguma maneira contribuiram na minha formação e na realização deste trabalho. 


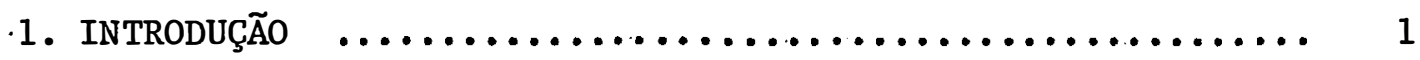

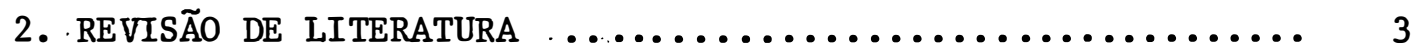

3. MATERIAL $\quad \ldots \ldots \ldots \ldots \ldots \ldots \ldots \ldots \ldots \ldots \ldots \ldots \ldots \ldots \ldots \ldots \ldots \ldots \ldots, 13$

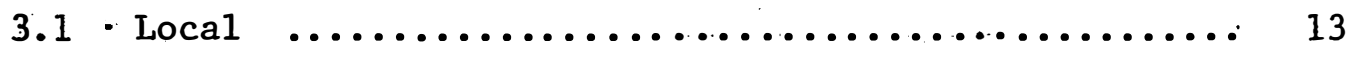

3.2 - Tanque Classe A Modificado $\ldots \ldots \ldots \ldots \ldots \ldots \ldots . . . \ldots 13$

3.2.1 - Tanque Classe A padrão .............. 14

3.2 .2 - Tanque intermediārio $\ldots \ldots \ldots \ldots \ldots \ldots \ldots, 14$

3.2 .3 - Tanque medidor $\ldots \ldots \ldots \ldots \ldots \ldots \ldots \ldots \ldots . . \ldots$

3.3 - Estação Meteorológi.ca Auxiliar .............. 19

3.3.1 - Tanque Classe A padrão ............... 19

3.3 .2 - Pluviômetro ...................... 19

3.3.3 - Anemômetro totalizador $\ldots \ldots \ldots \ldots \ldots \ldots .20$

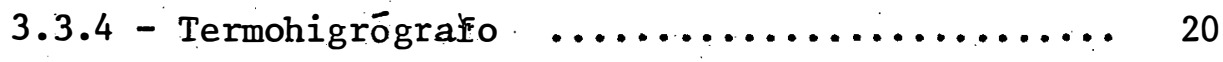

3.3.5 - Termômetros de máxima e mímina .......... 20

3.3 .6 - Evaporímetro de Piche $\ldots \ldots \ldots \ldots \ldots \ldots \ldots .20$

4. METODOS

4.1 - Tanque Classe A Modificado $\ldots \ldots \ldots \ldots \ldots \ldots \ldots \ldots .21$

4.1 .1 - Montagem e ajuste $\ldots \ldots \ldots \ldots \ldots \ldots \ldots \ldots . . \ldots 21$

4.2 - Testes Preliminares de Desempenho $\ldots \ldots \ldots \ldots \ldots \ldots .22$

4.2.1 - Aferição de escala de medida ........... 23

4.2.2 - Estimativa da variação da altura de equilíbrio devida à dilatação volumétrica dà águà. 24 
. 4.3.- Estimativa da Evapotranspiração Potencial (ETo)...... 25

4.3.1 - Método do Tanque :Classe A ............ 25

4.3 .2 - Método da Radiação Solar $\ldots \ldots \ldots \ldots \ldots \ldots \ldots . . \ldots 26$

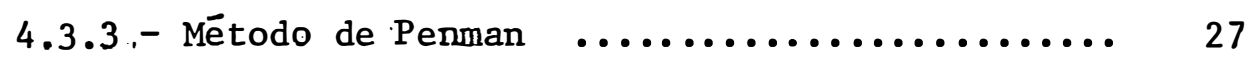

4.3 .4 - Método de Penman Simplificado ........... 28

4.3 .5 - Método de Thornthwaite $\ldots \ldots \ldots \ldots \ldots \ldots \ldots . \ldots 29$

4.4 - Anālise do Desempenho do Tanque Classe A Modificado com Relação ao Tanque Classe A. Padrão ........... 29

4.4 .1 - Em dias sem chuva ................. 29

4.4 .2 - Em dias com chuva $\ldots \ldots \ldots \ldots \ldots \ldots \ldots \ldots \ldots . \ldots . \ldots 30$

4.5 - Anālise do Desempenho dos Métodos de Estimativa de $\underline{\mathrm{E}}$ vapotranspiração Potencial ................ 31

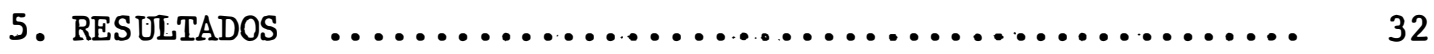

5.1 - Relativos aos Testes Preliminares de Desempenho dos Tanques Classe A.Modificados ............... 32

5.1 .1 - Aferição, da escala de medida .......... 32

5.1 .2 - Estimativa da variação da altura de equilíbrio devida à dilatação volumētricica da àgua.

5.2.- Relativos ao Desempenho dos Conjuntos Evaporimétricos Modificados ........................ 33

5.2 .1 - Evaporação em dias sem chuva $\ldots \ldots \ldots \ldots \ldots . . .33$

5.2 .2 - Evaporação em dias com chuva $\ldots \ldots \ldots \ldots \ldots . . .36$ 
5.3 - Relativos às Comparações de Estimativas de Evapotrans piração Potencial obtidas pelos Diferentes Métodos... 36

6. DISCUSSÃO DOS RESULTADOS $\ldots \ldots \ldots \ldots \ldots \ldots \ldots \ldots \ldots \ldots . . \ldots \ldots$

6.1.- Relativos aos Testes Preliminares de Desempenho dos Tanques Classe A Modificados $\ldots \ldots \ldots \ldots \ldots \ldots \ldots \ldots .638$

6.1 .1 - Aferição da escala de medida ............ 38

6.1.2 - Estimativa da variação da altura de eqüilíbrio devido à dilatação volúmétrica da água.. .

6.2 - Relativos ao Desempenho dos Tanques Classe A Modifica

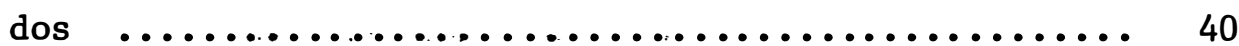

6.2.1 - Evaporação em dias sem chuva ............. 40

6.2.2 - Evaporação em dias com chuva ............. 41

6.3:- Relativos às comparações de Estimativa de Evapotranspiração Potencial: Obtida pelos Diferentes Métodos ... 42

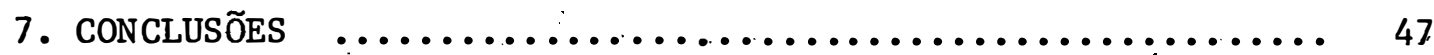

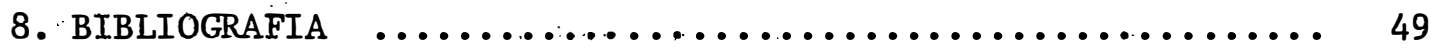

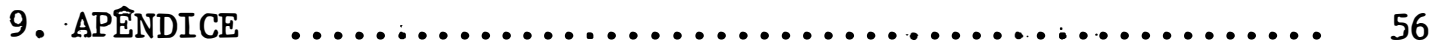




\title{
ANALISE PRELIMINAR DO DESEMPENHO DE UM SISTEMA \\ DE MEdidAs de EVAPORAÇÁ PARA TANQUe CLASSE A
}

\author{
Candidato: Malaquias da Silva Amorim Neto \\ Orientador: Prof. Dr. Nilson Augusto Villa Nova
}

\section{R E S U M O}

:0 presente trabalho diz respeito, ao projeto, constru ção e anālise de desempenho de um novo sistema de medida evaporimétrica, que é acoplado a um tanque classe "A" padrão convencional, dando-se ao sistema o nome de "Tanque Classe A Modificado". A viabilidade do sistema foi testada contra medidas simultâneas realizadas com o sistema clássico (tanque classe A padrão e micrômetro) revelan do, através de testes estatísticos, que o Tanque Classe A Modificado pode substituir com vantagens o sistema clássico, minimizando os erros de leitura que são cometidos, mesmo quando se dispõe de pessoal qualificados para esta operação, permitindo também a realização de medidas evaporimétricas com boa aproximação em dias de chuva.

Simultaneamente, tomando-se como referência a evapo"transpiração potencial estimada pelo novo sistema de medida, comparações são feitas com estimativas de evapotranspiração potencial rea 
lizadas por cinco processos convencionais utilizados, com a finalidade de avaliar o desempenho destes métodos. 


\section{$S U M M A R Y$}

The present work deals with desịgn, construction and performance analysis of a new system for evaporimetric measurements, which is coupled to a standard class A evaporation pan, and which was called "Modified Class A Pan". The viability of the system was checked against simultaneous measurements taken with the conventional system (standard class A pan plus micrometer depth gauge), indicating, from statistical. tests, that it can be made even by qualified staff, and making it possible to carry out evaporimentric measurements with good approximation on rainy, days.

Simultaneously, taking as reference the potential eva potranspiration estimated by the new system, comparions are made with potential evapotranspiration measurements carried out by five conventional processes, with a view to evaluating the performance of these methods. 


\section{TNTRODUÇAO}

A sempre crescente demanda de alimentos obriga a naçao a produzir para consumo interno, ou mesmo para exportação, uma máior quantidade de produtos agrícolas. Para este fim, āreas de cultivo, consideradas como impróprias pela irregularidade da disponibilidade natural de água, começam à ser utilizadas, graças aos recursos da irrigação, de aplicação cada vez mais crescente. Na condução racional de um projeto de irrigação, faz-se necessārio sempre determinar a quantidade e a frequência de aplicação de água. Para isto é de grande importância conhecer-se a demanda de àgua dos diferentes cultivos, demanda esta que è sempre referida ao valor padrão, denomidado de "evapotranspiração potencia1". Para determinação da evapotranspiração, diferentes métodos são sugeridos (pelo menos mais do que trinta são conhecidos), sendo poucos aqueles cuja aplicação é 
possível, seja por requererem conhecimento de parâmetros climāticos locais não disponíveis, ou seja pela complexidade de utilização. Atravēs de estudos conduzidos pela FAO (1979) como resultado condensado de inúmeros trabalhos de pesquisa, a mesma organização preconi $z a$, entre outros, o uso do Tanque Classe A para a estimativa da eva potranspiração potencial. Na utilização prática deste evaporímetro, nas condições usuais de trabalho, quase sempre são detectados erros operacionais, devido à relativa complexidade de leitura e manuseio. No presente trabalho procura-se simplificar o sistema de medidas de evaporação do Tanque Classe A, através de modifica ções introduzidas no sistema padrão sem perda da precisão devida, com a finalidade de minimizar os erros operacionais que se observam com muita frequência na prática rotineira, como os-de leitura do micrômetro, perdas de dados em dias de chuva, erros cometidos no reabastecimento e transporte de dados.

Paralelamente a este desenvolvimento, são comparados os resultados simultâneos de evapotranspiração potencial obtidos pe. las medidas do tanque e por alguns métodos usuais de estimativa. 
3.

\section{REVISÃO DE LITERATURA}

Inūmeros são os métodos climāticos sugeridos para es timativa da perda de água em superfícies cultivadas. Alguns como os métodos elaborados por PEXMMAN (1948 e 1956), RIJTEMA (1957), McJHOY (1961), JENSEN-HAISE (1963), LINGEN (1967) necessitam, para sua aplicação, dos parâmetros: temperatura do ar, umidade relativa, vento, insolação ou energia, estruturando-se en uma base física racional; e outros que correlacionam empiricamente alguns parâmetros cli máticos de simples medida, tais como: os métodos de THORNTHWAITE (1955), MAKKINK (1957), BLANEY-CRIDLLE (1964), entre outros. A esco Tha de um ou outro método dependerá quase sempre da disponibilidade de dados: Normalmente observa-se também que estes métodos estimam primariamente a "evapotranspiração potencial", tal como foi definida por THORNTHWAITE (1948), ou evapotranspiração de referência (FAO, 
1979), obtendo-se o valor específico de evapotranspiração de uma cultura qualquer, através de um fator corretivo denominado "coeficiente de cultura", o qual depende das condições ideais de umidade do solo e do estágio de desenvolvimento da cultura.

Investigando a confiabilidade das medidas dos métodos citados, um Comité Técnico da Divisão de Irrigação e Drenagem da Sociedade Americana de Engenharia Civil (Jensen, 1973, citado por BERLATO e MOLION, 1981), realizando comparações entre evapotranspiração medida e estimada constataram-se bons : resultados, desde que :se observasse o seguinte tempo mínimo de medida:

$$
\text { MĒTODO }
$$

Penman

Jensen-Haise

Makkink

Thornthwaite

Blaney-Cridlle
PERÍODO DE TEMPO MINIMO

Un dia

Cinco dias

Dez dias

Mensal

Mensal

Para condições do Estado de. São. Paulo, CAMARGo(1961) testou o método de Thornthwaite, com dados de evapotranspirômetros, considerando racional sua utilização tambēm em período mensal.

Em recente trabalho publicado pela FAO (1979), resul tado de observações condensadas de'inümeros experimentos realizados em vārias regiões do mundo, recomenda-se como racionais para estima tivas de evapotranspiração de referência os métodos de Penman, da 
Radiação Solar e aquele que utiliza o tanque Classe A padrão. Com relação a ește evaporímetro, inúmeras são as pesquisas que relatam a sua utilização em estimativas de evaporação e evapotranspiração. ASSIS e VIEIRA (1981), estudando as estimativas da evaporação do tanque Classe A para períodos de 1, 3, 5 e 7 dias, através de um modelo empïrico envolvendo dèficit de saturação do ar, observaram que a evaporação apresenta correlação com o déficit de saturação à temperatura média ou máxima do ar, superior a $80 \%$, com um erro de estimativa para temperatura média inferior a $1 \mathrm{~mm} / \mathrm{dia}$ e para temperatura máxima superior a $1 \mathrm{~mm} / \mathrm{dia}$.

A exposição de um tanque de evaporação influi consideravelmente nos resultados obtidos. LOMAS e SCHLESINGER (1970), es tudando a influência de obstáculos sobre o tanque, constataram que a colocação de quebra ventos, em dois locais e épocas diferentes, in fluem na evaporação do tanque nas seguintes proporções: para Mireta him no verão a diferença entre o tanque com proteção a $5 \mathrm{~m}$ e outro sem proteção foi de 10\%, jā em Eilot no inverno a diferença foi de 1\%. HANSON e RANZI (1977) verificaram que uma simples cerca de arbustos nas proximidades diminuiu de cerca de $14 \%$ a evaporação.

Às vezes é necessāria a cobertura do tanque com tela de arame para prevenir-se a utilização da água por animais. 0 'simples fato de se colocar uma tela protetora de arame, segundo . KALMA e STANiHILl (1969), reduziu a evaporação em $11 \%$ com relação ao tanque sem tela. CAMPBELL e PHENE (1976), colocando uma tela de 5 cm 
de malha observaram uma redução de $13 \%$ da evaporação. Também pesqui sadores da FAO (1976) verificaram que tanques cobertos com tela de arame reduzem a evaporação em 10\%. SILVA et alii (1981), estudando a influênicia de proteções sobre o tanque, observaram que a evaporação diminuia em $14,5 \%$ quanăo coberto com uma tela e 13,3\% com uma cerca de tela de malha de $1,5 \times 2,0 \mathrm{~cm}$. Jã a evaporação em tanques enterrados e coberto foi reduzida em $31 \%$.

0 estado de umidade do solo adjacente também influi nos resultados. DALE e SCHEERINGA (1977) determinaram que, para cada $10 \%$ de variação de umidade do solo adjacente há um aumento de 0,2 mrn/dia na evaporação.

E muito frequente, por questões de conservação,a pin tura das paredes e do fundo dos tanques: WARTENA e BORGHORST (1960), estudando o balanço de energia sobre o tanque, verificaram que o fundo em chapa galvanizada simples reflete em média $8 \%$ da radiação de ondas curtas absorvida, e que a modificação deste albedo pode ocasionar erros de medida.

OLIVEIRA (1971), estudando o comportamento do tanque Classe A para a região de Piracicaba, SP, em diferentes condições de exposição, determinou um fator médio anual de 0,72 para conversão da evaporação do tanque em evaporação de superfície livre d'àgua.

Procurando minimizar os "erros do operador", que ocorrem com o uso do micrômetro de gancho sia medida da evaporação do 
tanque, ALBERIO (1979) substituiu o sistema convencional por um sis tema acoplado ao tanque que constitui-se de um tanque abastecedor com uma regua milimetrada para medidas e um conjunto de sifões que fornece a referência de nîvel, obtendo com esta modificação para da dos diārios e médias de cinco dias, os seguintes coeficientes de cor relação, respectivamente, 0,9792 e 0,9935. ASSIS (1978), substituin do o micrômetro por uma escala graduada e mantendo o tanque sempre a nível constante, encontrou correlaçôes significativas com o siste ma convencional.

Grande é o número: de pesquisadores que estudam as re lações entre evapotranspiração potencial, necessidade de água de cul turas e a evaporação do tanque Classe A.

FUCHS et alii (1964), comparando, em cultura de algọ dão, a perda d'água calculada por processo gravimétrico e aquela es timada pelo método do tanque Classe $A$, constataram que ambos os métodos fornecem resultados similares. Todavia, os equipamentos e. tra balho necessārios foram dez vezes maiores pela gravimetria. Doss et alii (1964), trabalhando com forragens em vārios nịveis de umidade, obtiveram elevada correlação entre a evapotranspiração medida nos diferentes estágios de crescimento" e de umidade do solo, com a evaporação do tanque Classe A.

EKERN (1966), estudando evapotranspiração de grama em lisimetros, verificou que quando o solo se encontrava próximo à capacidade de campo, com evapotranspiração potencial alta, as necessi 
dades de água da vegetação era aproximadamente igual à evaporação do tanque Clasșe A. TOVEY et alii (1969), pesquisando gramĩneas, concluiram que estimativas de evapotranspiração realizadas pelo tanque em periodo semanal, concordam com as medidas realizadas na fase de desenvolvimento ativo, quando a cobertura do solo é plena.

EVANS (1971), relacionando evapotranspiração de arroz irrigado na Austrália, encontrou uma relação de 1,02 com a evaporação do tanque Classe $A$, em todas as fases do desenvolvimento. CRUCIANI (1972) observou que a evaporação do tanque Classe A e a evapotranspiração real são altamente correlacionadas nos três estägios do ciclo da cana-de-açúcar. Pesquisadores da EMBRAPA (197.8), correlacionando evaporação do tanque Classe A com a evapotranspiração do feijão, observaram que o tanque tem se mostrado como um bom indicador do consumo de àgua pela cultura.MATZENAÜER et alii (1981), estudando evapotranspiração do mịlho e sua relação com a evaporação do tanque Classe A, concluiram que esta relação foi menor durante a fase semeadura-emergência, aumentando progressivamente até a fase de pendoamento-espigamento, obtendo nesta fase o valor mäximo de 0,96 .

Vārios pesquisadores têm realizado trabalhos para dẹ terminar o coeficiente de proporcionalidade entre a evapotranspiração real e a evaporação do tanque Classe A de determinadas culturas, como: KRUTMAN (1963), THOMPSON (1965), THOMPSON e BOYEE (1967), CHANG et alii (1968), EARLY e GREGORIO (1971), CRUCIANI (1972), pa- 
ra cana-de-açúcar; DENMEAD e SHAW (1959), FRITSCHEN e SHAW (1961), DOSS et alii (1962), SCARDUA (1970), para milho; JUNIOR (1978), ENCARNAÇÃO (1980), para feijão.

ENCARNAÇÃO (1980), estimando o coeficiente de cultura para o feijão ao longo do ciclo, verificou que a estimativa da evapotranspiração potencial, através do tanque $\mathrm{Cl}$ asse A, entre outros modelos estudados, fornecem os valores mais próximos dos sugeridos pela FAO (1979).

Outros trabalhos têm sido desenvolvidos para comparar a evaporação e evapotranspiração estimada por métodos empíricos e a medida pelo tanque Classe A. STANHILL (1961), comparando a evapotranspiração potencial calculada por vários métodos que envolvem parâmetros climáticos, obteve os seguintes coeficientes de correlação para períodos mensais e semanais, respectivamente: Penman, 0,96 e 0,76; Thornthwaite, 0,94 e 0,73; Blaney e Criddle, 0,90 e 0,70; Makkink, 0,95 e 0,75; Tanque Classe A, 0,95 e 0,77; Radiação solàr, 0,91 e 0,77. Por outro 1ado, CHAPAS e REES (1963), comparando a eva poração medida em tanque Classe A com a estimada por métodos empíri cos, observaram que a estimada por Thornthwaite $\bar{e}$ superior à do tan que e que este método também superestima a evapotranspiração. Jà o método de Penman estima a evaporação com valores bem coerentes com os do tanque e a evapotranspiração calculada por ele é aproximadamente igual a de uma superfície livre de água. 
VILLA NOVA (1967), relacionando valores médios mensais de evaporação potencial estimada pelo método de Penman e medidos pelo tanque Classe A, encontrou um fator de conversão de 0,76.

Na prática da irrigação em culturas, vārios são os pesquisadores que têm utilizado o dado de evaporação do tanque clas se A para programar quantidades de água necessārias às culturas.

FUCHS e STANHILL (1963), pesquisando a utilização de evaporação do tạque classe A para estimar a irrigação necessāria à cultura do algodão, durante dois anos em 15 locais, cobrindo uma lar : ga variação de climas, solos e condições de planta, confirmaram a existência de um alto grau de correlação entre a evapotranspiração de campos irrigados e a evaporação do tanque.

GOLDBERG et alii (1966), estudando as necessidades hî dricas do amendoim e a evaporação do tanque Classe A; durante a esta ção de crescimento da cultura, observaram que o tratamento ótimo de irrigação foi o aplicado semanalmente em uma quantidade igual a $90 \%$ da evaporação do tanque.

JONES (1980), em estudos realizados no Havar̃, mostrou que para períodos mensais: (1) cana-de-açūcar irrigada por aspersão e sulcos, a evapotranspiração potencial é aproximadamente igual à evaporação do tanque Classe A; e, (2) quando irrigada por go tejo, a evapotranspiração potencial pode ser aproximadamente $15 \%$ me nor que a evaporação do tanque Classe A. 
A utilização de outros tipos de evaporimetros que não o tanque Classe A, parece não ser favorável. TANNER (1968) admite que atmômetros devido ao problema de tamanho e exposição, resultam em correlações complexas com a evapotranspiração, não viabilizando a sua utilização para esta estimativa.

Com relação ao evaporímetro de Piche, STANHILl(1962), estudando as relações entre evaporação Piche e evapotranspiração potencial, verificou que esta está altamente correlacionada com o ter mo aerodinâmico da fórmula de Penman, propondo sua utilização para estimar este termo. FERREIRA (1972) cita o fato de que, devido à sim plicidade operacional e baixo custo, o evaporímetro de Piche tem originado muita especulação quanto à utilização de seus dados. Cita também os trabalhos de Thornthwaite (ì954), Stanhill (1961) e Omar (1970), que concluem que o instrumento é inadequado para estimativas de evapotranspiração potencial, todavia, determinando certas cor relações com o termo aerodịnâmico de Penman.

vārios têm sido os trabalhos efetuados por pesquisadores da WMO (1966), em países diferentes, comparando o tanque clas se A com outros tipos de evaporímetros e atmometros. Entre eles podemos citar os efetuados nos territórios do leste Africano, onde correlacionaram-se média anual de evaporação do evaporímetro de Piche e o tanque Classe A, obtendo um coeficiente de 0,965. Já para a República Ārabe Unida, no período de 1958-1962, obteve-se uma relação de 0,64 para o evaporimetro de Piche ao ar livre e 1,03 quando 
protegido. Em Israel, para o perîodo de 1954-1960, obteve-se uma re lação de 1,06 para o evaporîmetro de Piche. No Kenya, comparando-se com o tanque Kenya, obteve-se 0,95 correlacionando-se valores diârios. Comparaçōes feitas em Poona (India) indicam que a relação de valores de um tanque de 20 pés de diâmetro e 10 polegadas de profun didade com o tanque Classe A é 0,78. Nos Estados Unidos, por comparaçôes durante um ano, obteve-se 0,77 na relação entre tanque Classe A e o lago Felt. Na União Soviética uma relação entre o tanque $20 \mathrm{~m}^{2}$ e o Classe A obteve-se 0,77 .

BROWN e HOLLSTED (1952), comparando a evaporaçāo do tanoue Classe A com a do tanque tipo Plant Industry em Hays, Kans, observaram que em 14 anos de dados a evaporaçäo do Plant Industry é 1,46 vezes maior que a do tanque Classe $\mathrm{A}$.

STANHILL (1958) desenvolveu um equipamento integrador de evaporação e precipitação, constituindo-se de um evaporímetro, um reservatório e um pluviómetro, acoplados de maneira que a quantidade d'água no equipamento correspondia à quantidade d'água retida no solo. Este equipamento foi utilizado como indicador de ir rigação, demonstrando ser tão preciso como qualquer outro método e tendo a vantagem de dar a indicação direta do déficit de umidade do solo. 
0 experimento em questão foi conduzido nas dependências do campo experimental do Departamento de Engenharia Rural da Escola-Superior de Agricultura "Luiz de Queiroz" (ESALQ), Piracicaba, SP, cujas coordenadas aproximadas são: Latitude $22^{\circ} 43^{\prime} \mathrm{S}$, 'Iongitude $47^{\circ} 38^{\prime} \mathrm{W}$ e altitude $560 \mathrm{~m}$.

\subsection{Tanque Classe A Modificado}

Entende-se por conjunto evaporimétrico modificado um sistema de medida de evaporação (Figura 1.A e 1.B), constituído de um tanque classe A padrão (A), um tanque intermediārio (I), e um tanque medidor (M), cujas características construtivas são as seguintes. 


\subsection{1 - Tanque C.lasse A padrão}

Tanque de chapa galvanizada no 22, diâmetro $120,7 \mathrm{~cm}$ e altura $25 \mathrm{~cm}$, montado sobre suportes de madeira a $15 \mathrm{~cm}$ do solo.

\subsection{2 - Tanque intermediārio}

Tanque cilíndrico, chapa galvanizada 22, diâmetro 30 cm, altura $20 \mathrm{~cm}$, com tampa (T) e suportes (S) de ferro, tripe de fer ro chato $1 \times 1 / 4$, altura $30 \mathrm{~cm}$, com três saídas (Figuras 1.A, 1.B, 2 . $A$ e 2.B).

a) Tubulação de PVC (E), acoplada ao corpo da válvula (K), torneada em latão, com agulha torneada em tefion (Y). Fixando o conjunto no corpo do tanque, porcas interna e externa (Z). Suportes de metal (V) acoplados à boia (B) acionam a agulha (Y), através da unha de ajuste: (W) (Figuras 1.A e 2.A)

b) Tubulação de alimentação do tanque classe A (P): situada prō xima ao fundo, diâmetro interno de $1 \mathrm{~cm}$.

c) Tubulação de drenagem (D): luva metālica de ferro (L), solda da no fundo do tanque, na qual se rosqueia:um tubo de latão (F) de altura regulável, vedado por junta de borracha e porca de aperto (G). As ligações entre os tanques foram feitas com tubo PVC transparente de $1 \mathrm{~cm}$ de diâmetro interno (H). 


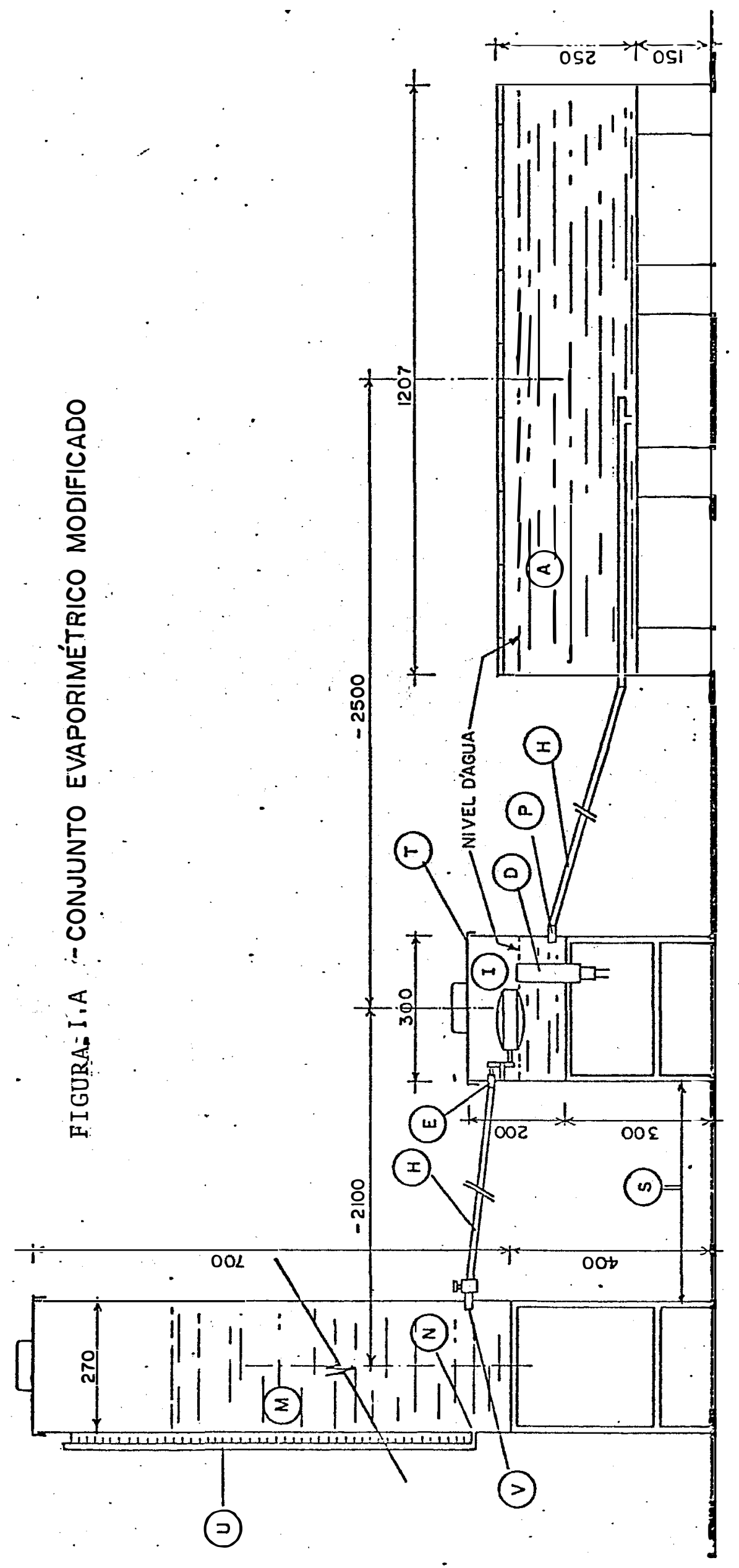


16.

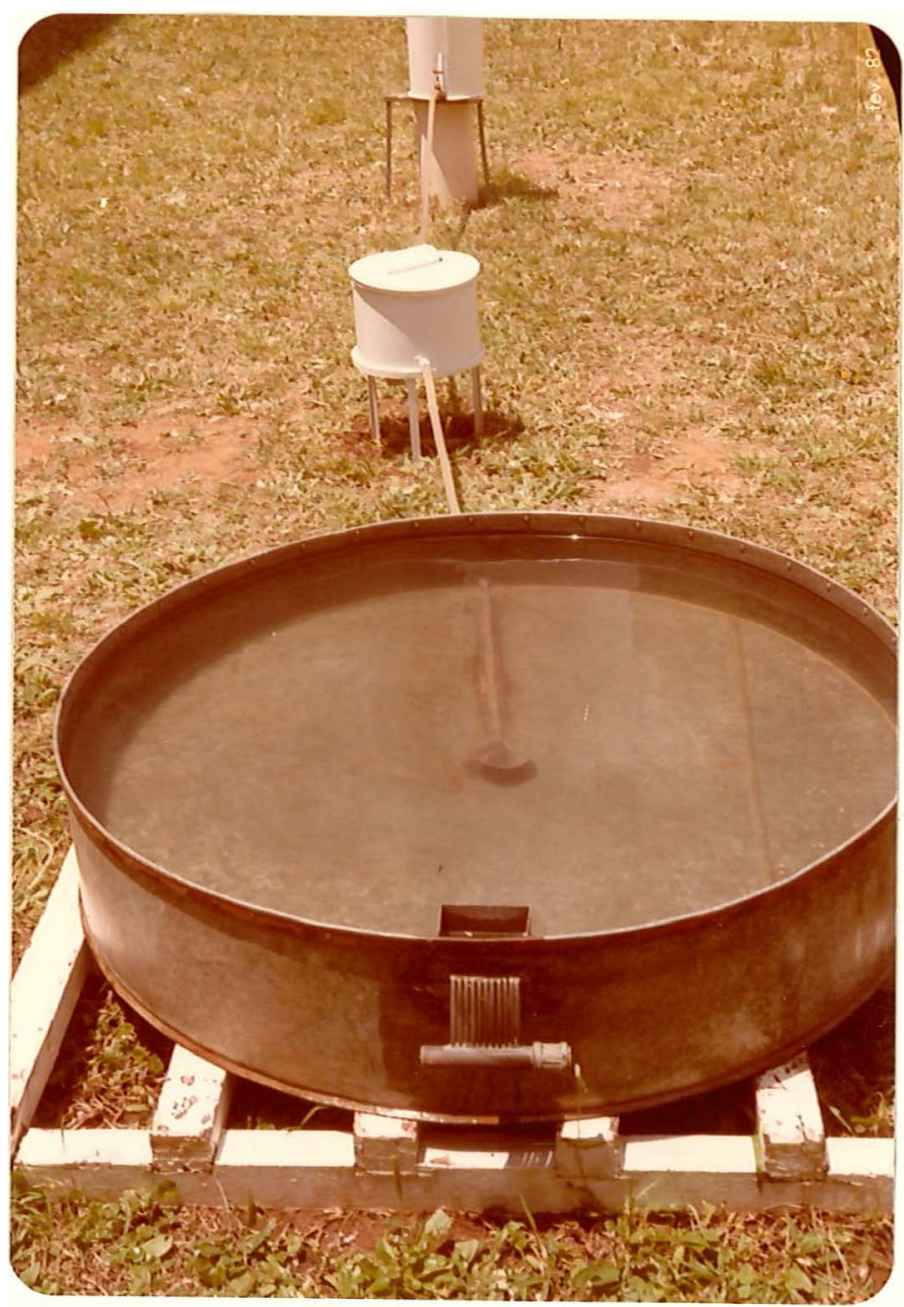

FIGURA. I, B - VISTA DO CONJUNTO EVAPORIMETRICO MODIFICADO, 


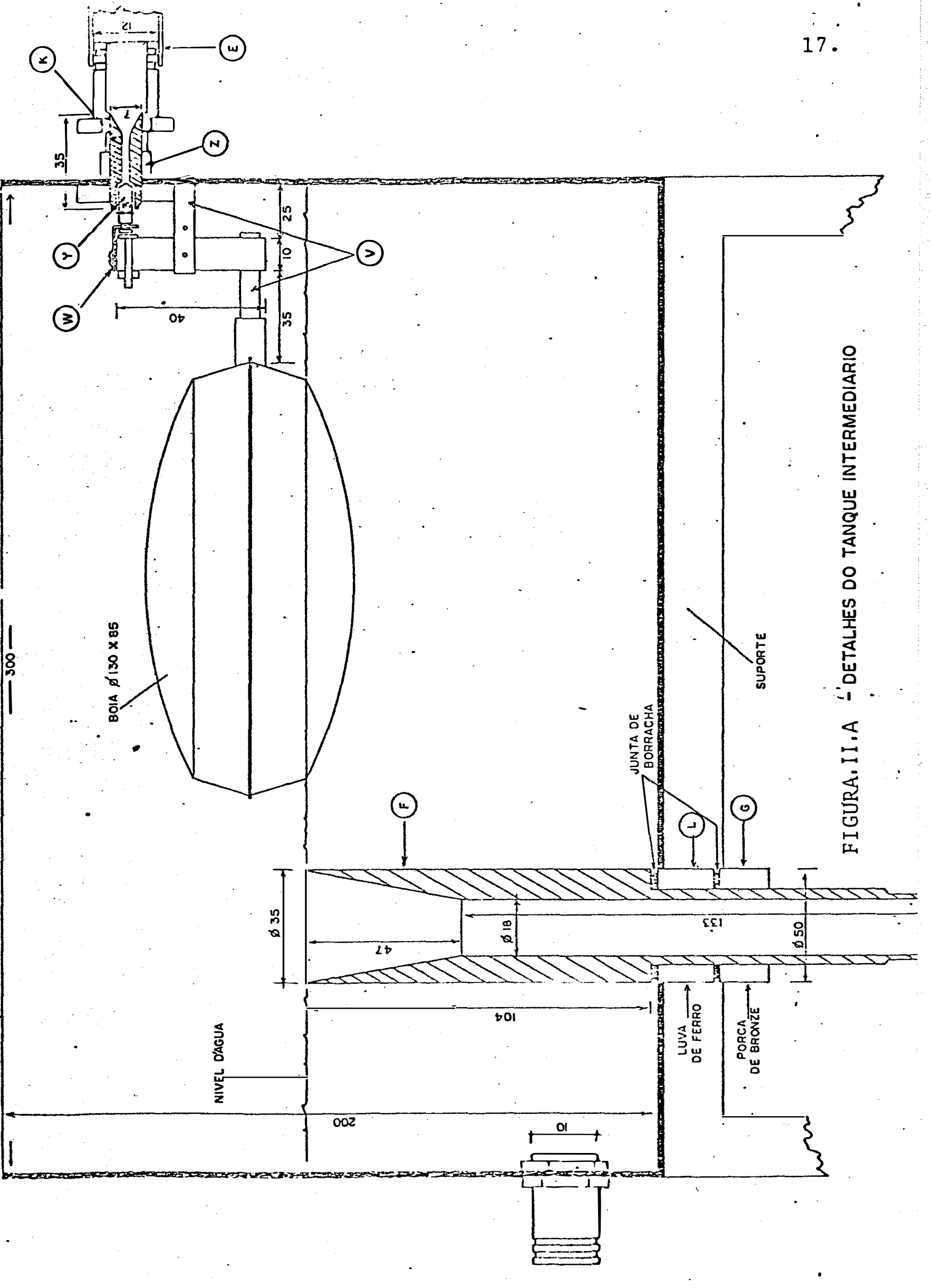


18.

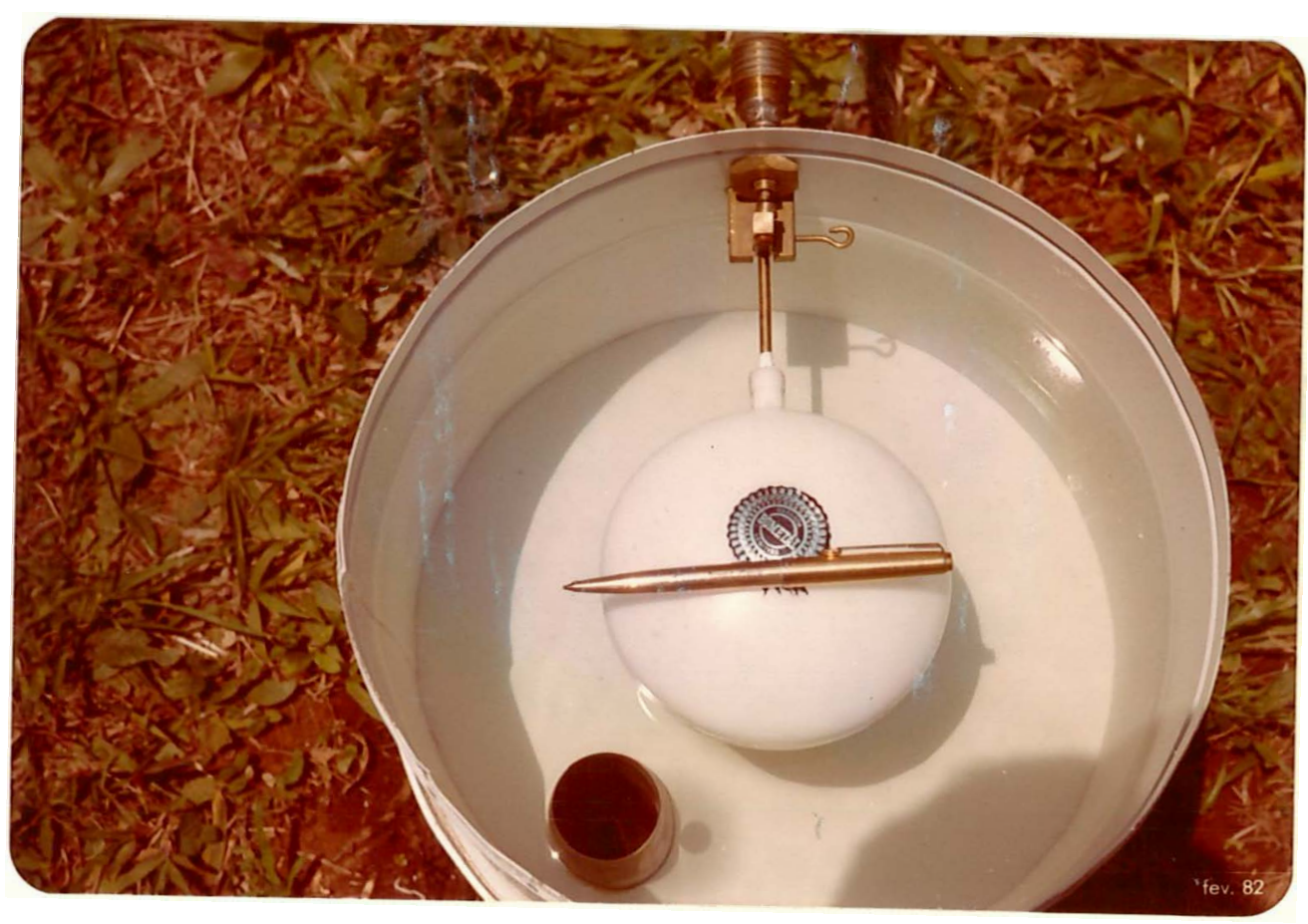

FIGURA, I I.B - VISTA DO TANQUE INTERMEDIÁRIO, 


\subsection{3 - Tanque medidor}

Cilíndrico, diâmetro $27 \mathrm{~cm}$, altura $70 \mathrm{~cm}$, chapa galvanizada 22 com tampa removível. Possui uma tomada para tubo de nível de $1 \mathrm{~cm}$ de diâmetro (N) e uma saída d'água (V)., diâmetro $1 \mathrm{~cm}$, para o tanque intermediārio. Um suporte (S) de ferro chato de 1 " $\mathrm{x}$ 40 c⿴囗十 (tripé) mantém o tanque na altura de trabalho $\because$ ( Figura 1.A). Uma escala graduada em mm de evaporação (U) foi fixada ao lon go do tubo de nível.

3.3 - Estação Meteorológica Auxitiar.

Para medida dos elementos de clima necessārios à con dução do experimento, montou-se uma estação meteorológica auxiliar, gramada e cercada segundo os padrões, com os seguintes componentes.

\subsection{1 - Tanque classe A padrão}

Idêntico ao jā descrito, porém com o sistema de medí das convencional constituído de poço tranquilizador e micrometro de gancho.

\subsection{2 - Plúviōmetro}

Tipo FUESS com $387 \mathrm{~cm}^{2}$ de ārea de recepção, instalado a $1,5 \mathrm{~m}$ de altura. 
20.

\subsection{3 - Anemômetro totalizador}

Anemômetro de canecas, marca Fuess com registro tota lizador, colocado a 2 in acima do nível do solo.

\subsection{3 - Termohigrógrafo}

Convencional, marca Fuess, de rotação semanal, previamente calibrado, instalado em abrigo termométrico padrão.

\subsection{5 - Termōmetros de māxima e mínima}

Convencionais, de coluna de mercúrio em vidro (máxima) e de àlcool em vidro (mínima) marca Fuess, previamente aferidos e instalados no abrigo termométrico padrão.

\subsection{6 - Evaporímetro de Piche}

Modelo clássico, instalado no abrigo termométrico pą drão. 
21.

\section{METODOS}

\section{1. - Conjunto Evaporimētrico Modificado}

Para colocar em marcha operaciona1, o conjunto evaporimétrico modificado passou pela seguinte série de operações.

\subsection{1 - Montagem e ajuste}

Os tanques dispostos de acordo com a Figura 1.A, pas saram pelas seguintes etapas de ajuste.

4.1.1.1 - Nivelamento do Tanque Classe A - realizado com régua e níve1 comum.

4.1.1.2 - Determinação do nível de equilíbrio do tanque intenmediārio: Esta operação foi realizada introduzindo-se $\bar{a}-$ gua pela tubulação (E) com a saída $P$ fechada, até 
cessar a admissão de água. Marcou-se então este nível com lápis na parte externa do tanque intermediārio.

4.1.1.3 - Regulagem da altura de trabalho do tanque intermediá rio: Esta altura foi obtida ajustando-se o suporte (com batidas e penetração no solo) até que ò nível marcado na parte externa do tanque intermediārio (I) . estivesse na altura correspondente a $6 \mathrm{~cm}$ abaixo da parte superior do Tanque Classe A. Assim procedendo, condicionou-se o nível d'água no Tanque Classe A, sem pre aproximadamente a $6 \mathrm{~cm}$ da borda, que é o nível mé dio entre 5 e $7 \mathrm{~cm}$ permissíveis para o Tanque Classe A padrão.

4.1.1.4 - Regulagem do dreno do tanque intermediārio: Uma vez determinado o nível d'água dentro do tanque intermediārio (nível de trabalho), soltando-se a porca de fixação $G$, rosqueou-se o tubo de dreno atē que sua extremidade superior estivesse a cerca de 0,1 m aci ma do nível d'água. .

\section{2 - Testes Preliminares de Desempenho}

Para avaliar-se preliminarmente as condições de desem penho do conjunto evaporimétrico modificado, procederam-se aos seguintes testes. 


\subsection{1 - Aferição da escala de medida}

Para verificação de possíveis erros construtivos, pro cedeu-se um teste da escala de medida que depende dos diâmetros dos tanques, da seguinte maneira. Sendo,

$V_{1}=$ volume de água evaporada no tanque classe A;

$\Delta \mathrm{h}_{1}=$ altura de água evaporada no tanque classe A;

$S_{1}=$ superfície do tanque Classe $A ;$

$\mathrm{v}_{2}=$ volume escoado do tanque intermediário para manter o nível constante;

$v_{3}=$ volume escoado do tanque medidor para manter o níve $ł$ constante;

$\Delta \mathrm{h}_{3}=$ altura de água escoado do tanque medidor;

$S_{3}=$ superfície do tanque medidor (II).

Todas as vezes que ocorrer a evaporação $\mathrm{V}$ teremos, de acordo com o balanço de água:

$$
\mathrm{v}_{1}=\mathrm{v}_{2}=\mathrm{v}_{3}=\mathrm{v}
$$

pois, os tanques medidor e intermediārio são vedados, portanto, a $\bar{u}-$ nica perda admissível, seria aquela por evaporação no tanque Classe A. Decorre que,

$$
v_{1}=v_{3}
$$

ou, ainda,

$$
\Delta \mathrm{h}_{1} \mathrm{~S}_{1}=\mathrm{h}_{3} \mathrm{~S}_{3}
$$


e também

$$
\Delta h_{3}=\Delta h_{1} \cdot \frac{S_{1}}{s_{3}}
$$

A altura de àgua que escoa do tanque medidor $\left(\Delta \mathrm{h}_{3}\right)$ se rá então $S_{1} / S_{s}$ vezes maior do que a altura de água evaporada.

0 teste de escala consistiu então de retirar-se repe tidos volumes do tanque $A$, medindo-se a variação de altura decorren te $\left(\Delta h_{1}\right)$ e colocar-se estes mesmos volumes no tanque medidor, medin do também a variação de altura ocorrida $\left(\Delta \mathrm{h}_{3}\right)$. A relação média entre a ārea dos tanques $\left(\bar{S}_{1} / \bar{S}_{3}\right)$ ficou expressa por:

$$
\frac{\overline{S_{1}}}{\overline{S_{i}}}=\frac{\Delta h_{3}}{\Delta h_{1}}=\frac{\sum \frac{n \cdot \Delta h_{3}}{\Delta h_{1}}}{n}
$$

onde n é o nūmero de repetições.

\subsection{2 - Estimativa da Váriação da Altura de Equilïbrio Devị} da à Dilatação Volumētrica da Ägua

Desde que a altura de equilíbrio das colunas d'água nos tanques deve variar em função da temperatura, estimou-se uma pro vãvel variação de altura de equilíbrio $(\Delta h)$ pelas seguintes relações. Sendo:

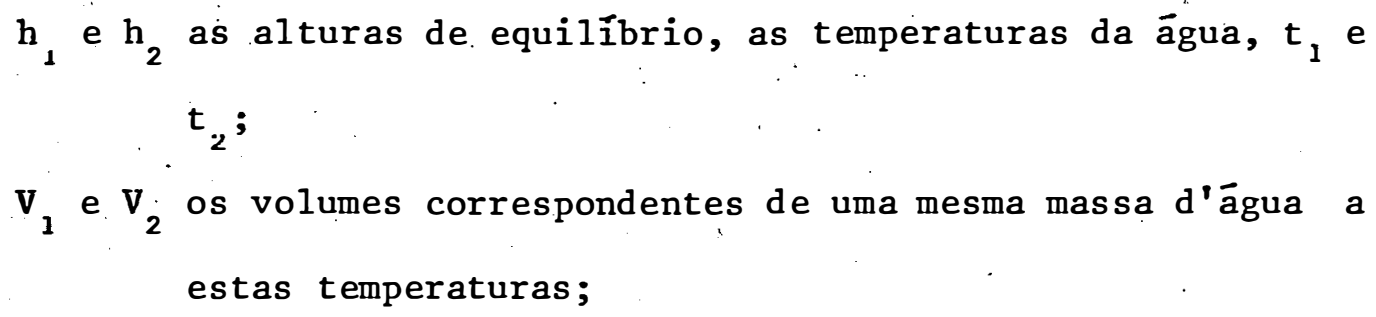


teremos uma variação de volume correspondente,

$$
\begin{aligned}
\dot{\Delta v}=v_{2}-v_{1} & =v_{v}\left[1+\alpha\left(t_{2}-t_{0}\right)\right]-v_{0}\left[1+\alpha\left(t_{1}-t_{0}\right)\right] \\
& =v_{v} \alpha\left(t_{2}-t_{1}\right),
\end{aligned}
$$

sendo $t_{0}$ a temperatura de referência, e $\alpha$, coeficiente de dilatação volumétrica da āgua.

Assim sendo, a variação total de altura de equilíbrio entre $t_{2}$ e $t_{1}$ será:

$$
\Delta h=\frac{\Delta V}{s_{1}}-\frac{v_{0} \alpha\left(t_{2}-t_{1}\right)}{s_{1}}=\frac{h_{0} s_{1}}{s_{1}} \alpha\left(t_{2}-t_{1}\right)
$$

ou ainda:

$$
\Delta h=h_{0} \alpha\left(t_{2}-t_{1}\right)
$$

expressão que nos permite estimar a amplitude de variação da altura de equilíbrio $\underline{h}$, em função das temperaturas extremas $t_{2}$ e $t_{1}$, obser vadas em um período, e da altura total da água no tanque classe A, considerada como $h_{0}$, desde que no intervalo de temperaturas conside radas, $\alpha$ pode ser tomado como constante.

4.3 - Estimativas da Evapotranspiração Pòtencial (ET $)$

Para estimativas da evapotranspiração potencial (ou de referência) utilizaram-se os seguintes métodos.

\subsection{1 - Método do Tanque $\mathrm{Cl}$ asse $\mathrm{A}$}

De acordo com as normas preconizadas pela FAO (1979)

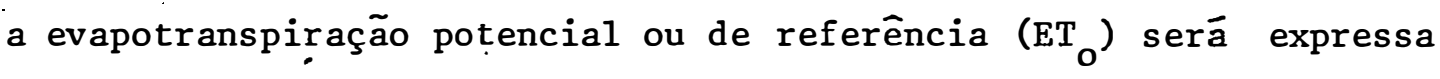


em função do Tanque Classe A, por:

$$
E T_{0}=K_{p} \cdot E C A \text {, }
$$

onde, $\mathrm{ECA}=$ evaporação medida no Tanque Classe $\mathrm{A}$ (mm/período);

$\mathrm{K}_{\mathrm{p}}=$ "coeficiente de Tanque", função da velocidade média do vento, umidade relativa média, e tipo de exposição do tanque (Tabela I do Apêndice).

\subsection{2 - Método da Radiação Solar}

A estimativa da evapotranspiração de referência pelo método da radiação solar $\left(E_{\mathrm{O}_{4}}\right.$, consiste na resolução das equações:

$$
\begin{aligned}
\mathrm{ET}_{\mathrm{O}_{4}} & =c \cdot \mathrm{w} \cdot \mathrm{R}_{\mathrm{s}} \\
\mathrm{R}_{\mathrm{S}} & =\mathrm{R}_{\mathrm{A}}\left(0,24+0,58 \frac{\mathrm{n}}{\mathrm{N}}\right),
\end{aligned}
$$

onde, $R_{S}=$ radiação de onda curta, estimada ao nível do solo (mm/ período);

$\mathrm{R}_{\mathrm{A}}=$ radiação extra terrestre, função do mês e latitude (Tabela II do Apêndice);

$\mathbf{w}=$ fator de ajuste dependente da temperatura média do ar e altitude (Tabela II do Apêndice);

$c=$ fator de ajuste dependente da velocidade e umidade rela tiva média do vento no período, obtido graficamente (Fi gura 3 do Apêndice). 
Para um melhor ajuste às condições locais, utilizou-se, no método, ao invés da equação original, aquela proposta por OMETTO (1968), determinada para as condições de Piracicaba, SP, ou seja,

$$
R_{s}=R_{A}\left(0,26+0,51 \frac{n}{N}\right)
$$

\subsection{3 - Método de Penman}

Para estimativa da evapotranspiraçāo potencial pelo método de Penman (ET ${ }_{05}$ ), utilizou-se a formulação original proposta pelo autor (PENMAN, 1948):

$$
\mathrm{ET}_{\mathrm{O}_{5}}=\frac{\frac{\Delta}{\gamma} \mathrm{H}+\mathrm{E}_{\mathrm{a}}}{\frac{\Delta}{\gamma}+1} \text {; }
$$

sendo,

$$
\begin{aligned}
H= & R_{A}\left(0,24+0,58 \frac{n}{N}\right)(1-a)-\sigma T_{a}^{4}(0,56-0,09 \sqrt{e})\left(0,1 \ldots+0,9 \frac{n}{N}\right) \\
E_{a}= & 0,35\left(1+\frac{11}{160}\right)\left(e_{s}-e\right) \\
\frac{\Delta}{\gamma}= & \text { fator adimensional dependente da temperatura média do ar } \\
& \text { no período (vide Tabela } v) ;
\end{aligned}
$$

onde os termos significam:

$$
\begin{aligned}
\mathrm{H} & =\text { balanço de energia radiante (mn/período); } \\
\mathrm{E}_{\mathrm{a}} & =\text { poder evaporante do ar à sombra (mm/período); } \\
\mathrm{U} & =\text { velocidade do vento }(\mathrm{km} / \mathrm{dia}) ; \\
\mathrm{n} / \mathrm{N} & =\text { razão de insolação média do período; }
\end{aligned}
$$


$a=$ poder refletor $(r=0,25)$;

$\overrightarrow{\mathrm{T}}_{\mathrm{a}}=$ temperatura média do ar no período considerado $\left({ }^{\mathrm{o}_{\mathrm{k}}}\right)$;

$\sigma=$ constante de Stefan Boltzman $\left(0,807 \times 10^{-10} \mathrm{cal} . \mathrm{cm}^{-2} \cdot \mathrm{min}^{-1} 0_{k}^{-4}\right.$;

e = valor médio de pressāo de vapor (mm $\mathrm{Hg} /$ período);

$e_{s}=$ tensão de saturação à temperatura $T_{a}(m \mathrm{Hg})$.

\subsection{4 - Mētodo de Penman Sìmpilifjcado}

0 método de Penman modificado refere-se a uma simpli ficação do método original, proposta por VILLA NOVA e OMETTO (1981), que consiste do seguinte conjunto de equações, vālidas para as condições de clima semelhantes às de Piracicaba, SP:

$$
\text { ET }_{\text {OG }}=\frac{\frac{\Delta}{\gamma}}{\frac{\Delta}{\gamma}+1}\left[\mathrm{R}_{\mathrm{A}}\left(0,19+0,23 \frac{\mathrm{n}}{\mathrm{N}}\right)\right]+0,28 \mathrm{E}_{\mathrm{p}}, \text { (mm/período) }
$$

vālida para o perỉodo primavera-verão, e

$$
\mathrm{ET}_{\mathrm{O} 6}=\frac{\frac{\Delta}{\gamma}}{\frac{\Delta}{\gamma}+1}\left[\mathrm{R}_{\mathrm{A}}\left(0,17+0,11 \frac{\mathrm{n}}{\mathrm{N}}\right)\right]+0,28 \mathrm{E}_{\mathrm{p}}, \cdot \text { (mm/período) }
$$

válida para o período outono-inverno, sendo $E_{p}$ a evaporação de $\mathrm{Pi}-$ che ao abrigo (molperíodo), e $\Delta / \gamma, R_{A}$ e $n / N$, com significado $j a ́$ des crito anteriormente.

Para o presente trabalho foi utilizada uma solução gräfica das equações propostas, demonstrada no Apêndice (Vide Figura 1 e 2). 


\subsection{5 - Método de Thornthwàite}

Estimou-se a evapotranspiração potencial pelo método de Thornthwaite, utilizando-se das Tabelas interpoladas por CAMARGO (1961) (vide (Tab.elas IV.A e IV.B do Apêndice). A evapotranspiração para cada pentada foi calculada em função das relações:

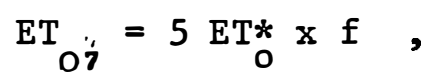

sendo, $\mathrm{ET}_{\mathrm{O}_{7}}=$ evapotranspiração, potencial corrigida (mm/5 dias);

$\mathrm{ET}_{0}^{*}=$ evapotranspiração potencial não corrigida (mm/dia) em função da temperatura média diāria e da temperatura média mensai;

f = fator de correção diārio para latitude de $22^{\circ} 43^{\prime} \mathrm{s}$ ( $\mathrm{P}_{\underline{i}}$ racicaba, SP) e para cada mês do ano.

4.4. - Anālise do Desempenho do Tanque Classe A Modificado com Relação ao Tanque Classe A.

\subsection{1 - Em dias sem chuva}

Para verificar-se se as evaporações observadas nos tanques modificados 1 e $2\left(E_{1}\right.$ e $\left.E_{2}\right)$ não diferiam entre si, e se sua média $\bar{E}_{12}\left(\bar{E}_{12}=\frac{E_{1}+E_{2}}{2}\right)$ não diferia daquela observada no tanque padrão $\left(E_{\mathrm{p}}\right)$, procederam-se às seguintes anālises estatísticas.

Tomando-se por base os dados diärios:dos meses de mar ço, abril, maio, junho :e julho de 1980 e os dados globais desŁe período, 
realizaram-se os seguintes confrontos para dados pareados, utilizan do-se o teste $t$.

a) $E_{1}$ versus $E_{2}$ (para valores diārios e globais).

b) $\bar{E}_{12}$ versus $E_{p}$ (para valores diärios e globais).

c) $E_{1}^{\prime}$ versus $E_{2}^{\prime}$ (para valores acumulados de três dias).

d) $\bar{E}_{12}^{\prime}$ versus $E_{p}^{\prime}$ (para valores acumulados de três dias).

\subsection{2 - Em dias com chuva}

Para os dias de chuva, nos quais os dados de $E_{1}$ e $E_{2}$ discrepavam daqueles obtidos de $\mathrm{E}_{\mathrm{p}}$, corrigiram-se os valores de $\mathrm{E}_{\mathrm{p}}$ através de um simples balanço hỉdrico (casos nos quais o tanque padrão não chegarä a transbordar), ou seja, $\mathrm{E}_{\mathrm{p}}=\mathrm{L}_{1}+\mathrm{P}-\mathrm{L}_{2}$, onde:

$E_{p}=$ evaporação corrigida do tanque padrão;

$\mathrm{L}_{1}=$ leitura micrométrica do dia anterior;

$\mathrm{L}_{2}=$ leitura micrométrica do dia posterior;

$\mathbf{P}=$ precipitação medida no pluviômetro.

Os valores de $\mathrm{E}_{\mathrm{p}}$ assim corrigidos, foram comparados $\operatorname{com} E_{1}$ e $E_{2}$, com a finalidade de verificar a viabilidade desta correção. 
4.5 - Anālise do Desempenho dos Métodos de Estimativa de Evapo- transpiração Potencial

Tomando como valor mais próximo do verdadeiro o valor médio de $\mathrm{ET}_{\mathrm{O}_{1}}$ e ET $\mathrm{O}_{2}\left(\overline{\mathrm{ET}}_{\mathrm{O}_{12}}\right)$, valor "medido" de evapotranspiração potencial, efetuou-se um estudo de regressão linear, tanto para valores diārios, como para valores de pentadas, entre as seguintes estimativas:
a) $\overline{\mathrm{ET}}_{\mathrm{O}_{12}} \times \overline{\mathrm{ET}}_{\mathrm{O}_{3}}$
b) $\overline{\mathrm{ET}}_{\mathrm{O}_{12}} \mathrm{x} \overline{\mathrm{ET}}_{\mathrm{O}_{4}}$
c) $\overline{\mathrm{ET}}_{\mathrm{O}_{12}} \mathrm{x} \overline{\mathrm{ET}}_{\mathrm{O}_{5}}$
d) $\overline{\mathrm{ET}}_{\mathrm{O}_{12}} \times \overline{\mathrm{ET}}_{\mathrm{O}_{6}}$
e) $\overline{\mathrm{ET}}_{\mathrm{O}_{12}} \mathrm{x} \overline{\mathrm{ET}}_{\mathrm{O}_{7}}$ 
32.

\section{RESULTADOS}

5.1 - Relativos aos Testes Preliminares de Desempenho dos Tanques Classe A Modificados

\subsection{1 - Aferição da escala de medida}

No Quadro I do Apêndice, são demonstrados os valores simültâneos de $\Delta \mathrm{h}_{3} / \mathrm{h}_{1}$ obtidos pela metodologia exposta, assim como o valor médio do valor de $\mathrm{S}_{1} / \mathrm{S}_{3}$, para cada conjunto evaporimétrico modificado, que nos demonstraram a relação média construtiva obtida entre as seções dos tanques medidores e os tanques evaporimétricos classe $A$. 
33.

\subsection{2 - Estimativa da variação da altura de equilībrio de- vido à dilatação volumétrica da āgua}

De acordo com o exposto no método, a provável amplitude de variação da altura de equilíbrio $\Delta h$, sendo expressa por

$$
\Delta h=h_{0} \alpha\left(t_{2}-t_{1}\right), \quad \text {. }
$$

admitindo que, durante um período qualquer a temperatura da água do tanque varie de $\left(t_{2}-t_{1}\right)$, sendo $\propto=0,207 \times 10^{-3} o_{C}^{-1}$, e $h$ aproxi madamente $225 \mathrm{~mm}$, obter-se-ão as seguintes variações da altura de equilỉbrio da água no tanque intermediärio $(\Delta \mathrm{h})$ :

$\begin{array}{cc}\Delta \mathrm{h} & \mathrm{t}_{2}-\mathrm{t}_{1} \\ 0,5 \mathrm{~mm} & 10{ }^{\circ} \mathrm{C} \\ 0,7 \mathrm{~mm} & 15{ }^{\circ} \mathrm{C} \\ 0,9 \mathrm{~mm} & 20{ }^{\circ} \mathrm{C}\end{array}$

5.2 - Relativos ao Desempenho dos Conjuntos Evaporimétricos Modi ficados

\subsection{1 - Evaporação em dias sem chuva}

No Quadro II do Apêndice são relatados os valores diā rios simultâneos de evaporação medida pelos conjuntos evaporimétricos modificados $\left(E_{1}\right.$ e $E_{2}$ ) e aqueles obtidos pelo tanque padrão $E_{p}$. Relativas a estes dados procederam-se às seguintes análises:

a) Confronto entre os dados observados de $E_{1}$ e $E_{2}$ com a finali dade de verificar se $E_{1}$ difere estatisticamente de $E_{2}$ na escala diā 
ria, considerando-se os meses em separado e o período global. 0 tes te $t$ aplicado revelou os seguintes resultados.

Quadro A - Confronto de $E_{1}$ e $E_{2}$.

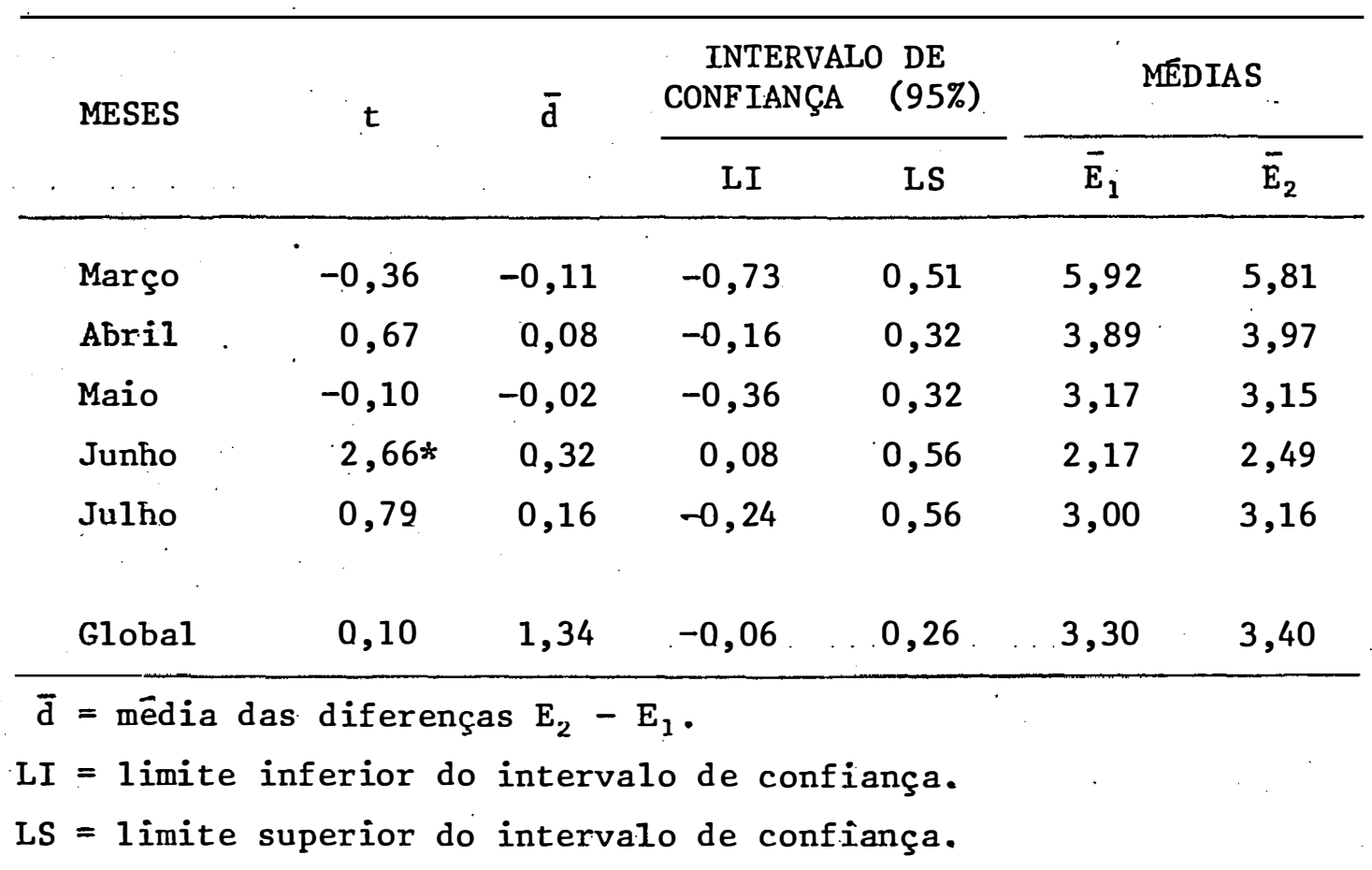

b) Confronto entre os dados observados de $\bar{E}_{1,2}$ e $E_{p}$ com a finalidade de verificar se $\bar{E}_{1,2}$ difere estatisticamente de $E_{p}$ na escala diāria, considerando-se os meses em separado e o período global, 0 teste $t$ aplicado revelou os seguintes resultados: 
Quadro B - Confronto de $\bar{E}_{1,2}$ e $E_{p}$.

\begin{tabular}{|c|c|c|c|c|c|c|}
\hline \multirow{2}{*}{ MESES } & \multirow{2}{*}{$t$} & \multirow{2}{*}{$\bar{d}$} & \multicolumn{2}{|c|}{$\begin{array}{l}\text { INTERVALO DE } \\
\text { CONF IANÇA ( } 95 \%)\end{array}$} & \multicolumn{2}{|c|}{ MEDIAS } \\
\hline & & & LI & LS & $E_{1,2}$ & $\bar{E}_{p}$ \\
\hline Março & 1,64 & 0,30 & $-0,06$ & 0,66 & 5,86 & 5,56 \\
\hline Abril & $-0,29$ & $-0,03$ & $-0,23$ & 0,17 & 3,96 & 3,99 \\
\hline Maio & 1,54 & 0,14 & $-0,04$ & 0,32 & 3,17 & 3,02 \\
\hline Junho & $\cdot-0,07$ & $-0,01$ & $-0,21$ & $0,19^{\circ}$ & 2,33 & 2,34 \\
\hline Julho & $-0,08$ & $-0,02$ & $-0,52$ & 0,48 & 3,10 & 3,12 \\
\hline Global & 1,26 & 0,07 & $-0,03$ & $-0,17$ & 3,36 & 3,30 \\
\hline
\end{tabular}

No Quadro III do Apêndice são relatados os̀ valores simúltâneos acumulados (para 3 dias) de $\mathrm{E}_{\mathrm{p}}^{\prime}$ (evaporação do tanque padrão), $E_{1}^{\prime}$ e $E_{2}^{\prime}$ (evaporação dos tanques modificados) e $\bar{E}_{12}^{\prime}$, a média de $E_{1}^{\prime}$ e $E_{2}^{\prime}$ para 3 dias. Relativas a estes dados, procederam-se às seguintes anālises:

a) Confronto entre os dados acumulados para 3 dias de $E_{1}^{\prime}$ e $E_{2}^{\prime}$ com a finalidade de se verificar se $E_{1}^{\prime}$ difere estatisticamente de $E_{2}^{\prime}$, no período global. 0 teste $t$ aplicado revelou os seguintes resultados:

Quadro C - - Confronto de E' e $\mathrm{E}_{2}^{\prime}:$

\begin{tabular}{cccc}
\hline & & & \multicolumn{2}{c}{ INTERVALO DE } & CONFIANÇA (95\%) \\
\cline { 3 - 4 } & & LI & LS \\
\hline 1,25 & 0,25 & $-0,15$ & 0,65 \\
\hline
\end{tabular}


- b) Confronto entre os dados acumulados de $\bar{E}_{1,2}^{\prime}$ e $E_{p}^{\prime}$, com a fina lidade de se verificar se $\bar{E}_{1,2}^{\prime}$ difere estatisticamente de $E_{p}^{\prime}$, no período global. O teste $t$ aplicado revelou os seguintes resultados. Quadro D - Confronto de $\bar{E}_{12}^{\prime}$ e $E_{P}^{\prime}$.

\begin{tabular}{ccccc}
\hline \multirow{2}{*}{} & $\overline{\mathrm{d}}$ & \multicolumn{2}{c}{ INTERVALO DE CONFIANÇA (95\%) } \\
\cline { 3 - 4 } &. & $\mathrm{LI}$ & LS \\
\hline 1,42 & 0,22 & $-0,10$ & 0,54 \\
\hline
\end{tabular}

\subsection{2 - Evaporação em dias com chuva}

Os valores de evaporação en dias de chuva $\mathrm{E}_{\mathrm{p}}$, evaporação corrigida $E_{p c}$ e evaporação dos tanques $E_{1}$ e $E_{2}$ são relacionados no Quadro IV do Apêndice.

5.3 - Relativos às Comparações de Estimativas de Evapotranspiração Potencial Obtidas pelos Diferentes Mētodos

No Quadro V do Apêndice são relatados os valores obtidos de evapotranspiração potencial estimada pelos diferentes méto dos considerados.

Com a finalidade de testar os diferentes métodos de estimativa de evapotranspiração potencial, procedeu-se um estudo de regressão linear simples e aplicaçâo do teste $\mathrm{F}$, tomando-se como mé 
todo padrão a evapotranspiração potencial obtida pelos tanques modị ficados (média $\mathrm{ET}_{\mathrm{O}_{1}}$ e $\mathrm{ET}_{\mathrm{O}_{2}}$ ) em dois casos a saber:

a) Regressões de $\overline{\mathrm{ET}}_{\mathrm{O}_{1,2}} \mathrm{x}$ diferentes métodos $\left(\mathrm{ET}_{\mathrm{O}_{3}}, \mathrm{ET}_{\mathrm{O}_{4}}, \mathrm{ET}_{\mathrm{O}_{5}}\right.$,

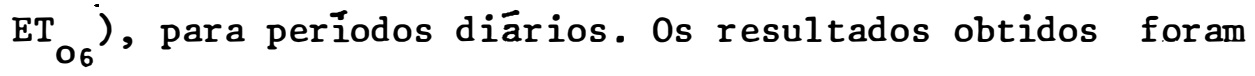
os seguintes:

Quadro E - Regressões de $\overline{\mathrm{ET}}_{\mathrm{O}_{12}} \mathrm{x}$ diferentes métodos.

\begin{tabular}{|c|c|c|c|c|}
\hline MÉTODO & Regressão & $\mathrm{R}^{2}$ & $\mathbf{R}$ & Teste $\mathrm{F}$ \\
\hline TCA padrão & $\overline{\mathrm{ET}}_{\mathrm{O}_{12}}=-0,326+1,091 \mathrm{ET} \mathrm{O}_{3}$ & 0,757 & 0,870 & $287,474 * *$ \\
\hline Radiação solar & $\overline{\mathrm{ET}}_{\mathrm{O}_{12}}=-0,187+0,808 \mathrm{ET}_{\mathrm{O}_{4}}$ & 0,645 & 0,803 & $203,483 * *$ \\
\hline Penman convencional & $\overline{\mathrm{ET}}_{\mathrm{O}_{12}}=0,247+1,003 \mathrm{ET}_{\mathrm{O}_{5}}$ & 0,468 & 0,684 & $85,581 * *$ \\
\hline Penman modificado & $\overline{\mathrm{ET}}_{\mathrm{O}_{12}}=-0,506+1,088 \mathrm{ET} \mathrm{O}_{6}$ & 0,616 & 0,785 & $147,873 * *$ \\
\hline
\end{tabular}

b) Regressões de $\overline{\mathrm{ET}}_{\mathrm{O}_{12}} \mathrm{x}$ diferentes métodos $\left(\overline{\mathrm{ET}}_{\mathrm{O}_{3}}, \overline{\mathrm{ET}}_{\mathrm{O}_{4}}, \overline{\mathrm{ET}}_{\mathrm{O}_{3}}\right.$, $\overline{\mathrm{ET}}_{\mathrm{O}_{6}}$ ), para períodos de 5 dias. Os resultados obtidos foram os seguintes:

Quadro F - Regressões de $\overline{\overline{\mathrm{ET}}_{\mathrm{O}_{12}}} \mathrm{x}$ diferentes métodos.

\begin{tabular}{llllll}
\hline \multicolumn{1}{c}{.. METODO } & Regressão & $\mathrm{R}^{2}$ & $\mathrm{R}$ & Teste $\mathrm{F}$ \\
\hline TCA padrão & $\overline{\mathrm{ET}}_{\mathrm{O}_{12}}=$ & $-0,134+0,994 \overline{\mathrm{ET}}_{\mathrm{O}_{3}}$ & 0,797 & 0,893 & $70,836 * *$ \\
Radiação solar & $\overline{\mathrm{ET}}_{\mathrm{O}_{12}}=-0,342+0,875 \overline{\mathrm{ET}}_{\mathrm{O}_{4}}$ & 0,872 & 0,934 & $123,773 * *$ \\
Penman convencional & $\overline{\mathrm{ET}}_{\mathrm{O}_{12}}$ & $=0,267+1,001 \overline{\mathrm{ET}}_{\mathrm{O}_{5}}$ & 0,689 & 0,830 & $39,988 * *$ \\
Penman modificado & $\overline{\mathrm{ET}}_{\mathrm{O}_{12}}=-0,398+1,069 \overline{\mathrm{ET}}_{\mathrm{O}_{6}}$ & 0,769 & 0,877 & $59,692 * *$ \\
Thornthwaite & $\overline{\mathrm{ET}}_{\mathrm{O}_{12}}$ & $=1,435+0,596 \overline{\mathrm{ET}}_{\mathrm{O}_{7}}$ & 0,263 & 0,513 & $6,426 *$ \\
\hline
\end{tabular}


6. DISCUSSAO DOS RESULTADOS

6.1. - Relativos aos Testes Preliminares de Desempenho dos Tanques Classe A Modificados

6.1.1 - Aferição da escala de medida

De acordo com a metodologia descrita, os dados do Qua dro I demonstram uma relação média de $1: 20,2$ (conjunto evaporimétrico 2) e 1:20,4 (conjunto evaporimétrico 1), entre altura de água evaporada no Tanque Classe A, e altura de água fornecida pelo tanque medidor, ou seja, para cada mn de āgua evaporada no tanque A teremos respectivamente 20,2 e 20,4 mn de abaixamento de nível no tanque medidor. Apesar dos diâmetros construtivos terem sido projetados para que esta relação fosse: 1:20, na prática não se conseguiu obter tal proporção. Para corrigir este defeito constrùtivo, utilizou-se no tanque medidor uma escala normal ( $2 \mathrm{~cm}$ igual a $1 \mathrm{~mm}$ c.de evapora- 
ção, ou seja, 1:20), multiplicando-se os valores obtidos pelos fato res de correção, respectivamente $0,99,\left(\frac{200}{202}\right)$ e $0,98,\left(\frac{200}{204}\right)$, sanando assim esta deficiência.

\subsection{2 - Estimativa da variação da altura de equilĩbrio de- vido à dilataçāo volumétrica da āgua}

Como ficou demonstrado no capítulo de Resultados, existe uma variação $\Delta \mathrm{h}$ de altura de equilíbrio de água nos tanques, que pode impedir que em determinado instante haja fluxo pela válvu1a ou vice-versa. Exemplificando: admitindo que em certo instante a evaporação seja da ordem de 0,1 mm/hora, e que durante este interva 1o de tempo ou mais a temperatura da água baixe para $10^{\circ} \mathrm{C}$, de acordo com os cálculos efetuados, deveremos ter uma alimentação de 0,5 mn' de āgua devido a contração de volume. Embora praticamente tal efeito não deva influir nas medidas, pois entre duas observações é pouco provável a ocorrência de tal variação de temperatura, nota-se que por causa deste efeito, durante o dia principalmente, a válvula para de debitar āgua, compensando este efeito com débito mais veloz nas horas de menor temperatura. Convém notar também, que esta fonte de erro deva: diluir-se, porque via de regra, segundo recomendações da FAO (1979), os dados de evapotranspiração potencial estimados pe1o tanque classe A tornam-se mais consistentes para intervalos de medida superiores a 5 dias. Tal efeito deve explicar o fato observa do de que, no período noturno, por vezes, a quantidade de água debi 
tada pelo tanque medidor, era maior no período noturno do que no diurno.

Estas estimativas de variação provável de nível foram tambēm necessārias para determinar a "altura de guarda" do "dreno do tanque intermediário para evitar problemas de ... extravasamento. Assim, manteve-se para. os dois tanques uma "guarda" de 1 mm. E ōbvio que nos períodos de chuva, esta condições determinou correções aditivas de pelo menos um milímetró nas leituras efetuadas.

6.2. - Relativos ao Desempenho dos Tanques Classe A Modificados

\subsection{1 - Evaporação em dias sem chuva}

a) Confronto entre $E_{1}$ e $E_{2}$ (medidas diārias)

De acordo com os dados do Quadro A, os dois tanques modificados não apresentaram dif̣erenças de comportamento quanto às estimativas de evaporação, com exceção do mês de junho no qual o valor de $t$ revelou-se significativo. Atribui-se este fato à interferência resultante de fatores alheios ao experimento (vandalismo) observados frequentemente neste período. Apesar disto, nota-se que na anālise realizada para o período global, a diferença existente entre os tanques $E_{1}$ e $E_{2}$ não foi significativa. 
b) Confronto entre $\bar{E}_{12}$ e $E_{p}$ (medidas diārias)

Assumindo-se que $E_{1}$ não difere de $E_{2}$, para avaliar o desempenho dos conjuntos modificados, com relação ao padrão, $\mathrm{E}_{\mathrm{p}}$, con siderou-se a médias destes dois valores, com o objetivo de elimina rem-se problemas decorrentes da exposição diferencial dos dois sistemas. Conforme a anālise exposta no Quadro B, não houve diferença significativa entre $\bar{E}_{12}$ e $E_{p}$, tanto para valores diärios de cada mês em separado, e para.o período global.

c) Confronto entre $E_{j}^{\prime}$ e $E_{2}^{\prime}$ (medidas acumuladas de 3 dias)

De acordo com os resultados demonstrados no Quadro C, não existe diferença significativa nos dados analisados para o período global.

d) Confronto entre $\bar{E}_{12}$ e $E_{p}^{\prime}$ (medidas acumuladas de 3 dias)

De acordo com os resultados da anālise demonstrados no Quadro D, não existe, como era de se esperar, diferenças signifí cativas nos dados analisados para o período global.

\subsection{2. - Evaporação em dias com chuva}

Para verificar a eficiência do conjunto evaporimétrí co em dias de chuva, separaram-se os dados conforme o Quadro :.... IV. Observa-se, por ele, que nos dias de transbordamento (15/04,03/05 e 06/06) como era de se esperar, não se pode avaliar a evaporação do 
tanque padrão, pois $\mathrm{L}_{2}$ fica indeterminado. Nos dias em que não exis te transbordamento verifica-se que é possível corrigir em alguns ca so os dados do tanque padrão, com auxîlio do pluviômetro, existindo porém situạções nas quais esta correção determina valores discrepan tes (dias 03/04 e 04/04), principalmente quando a chuva é associada a vento e turbilhões. Embora admitindo que um maior número de obser vaçōes seja necessārio para uma anālise conclusiva, de uma maneira geral, pela repetiçäo: " de valores que se observou nos conjuntos evaporimétricos, pode-se acreditar na eficiência destes sistemas,pa ra medidas em dias de chuva.

\section{3 - Relativos às Comparações de Estimativa de Evapotranspiração Potencial Obtida Pelos Diferentes Mētodos}

Para estimativas de evapotranspiração potencial (ou de referência), vārios mêtodos são utilizados na prätica. Objetivan do determinar a consistência de resultados fornecidos pelos métodos de Penman, do Tanque Classe A padrão, da Radiação Solar (recomendados pela FAO, 1979), de Thornthwaite, bastante utilizado para fins climäticos, e do método de Penman modificado por VILLA NOVA e OMETTO (1981), compararam-se os resultados simultâneos destes métodos, com aqueles estimados pelas evaporaçōes dos conjuntos evaporimétricos; associadas a coeficientes de tanque. Elegeu-se tal método como padrão de comparação porque suas estimativas são baseadas em medidas, que, teoricamente devem integrar melhor os efeitos conjugados do clima no processo evaporativo. 
No Quadro E, onde se analisam as regressões $\overline{\mathrm{ET}}_{\mathrm{ol2}} \mathrm{x}$ diferentes mẹtodos para períodos diārios, nota-se,como era de se es perar, uma boa correlação $\overline{\mathrm{ET}}_{\mathrm{ol}} \times$ Tanque Classe A padrão $(x=0,87)$ seguida pelo método da radiação solar $(r=0,803)$, Penman modificado $(r=0,785)$ e Penman convencional $(r=0,684)$.

Os resultados obtidos, de acordo com o teste $F$ são significativos ao nível de 1\%. Na Figura A está demonstrada a dis- . persão em torno das retas de regressão, observamos que os maiores desvios acontecem para valores muito baixos de evapotranspiração po tencial, podendo isto ser explicado pelo grau de sensibilidade das fórmulas em estimar esta evapotranspiração em dias em que seu valor è mínimo.

No Quadro F, onde se analisam as regressóes $\overline{\mathrm{ET}}_{\mathrm{ol2}} \mathrm{x}$ diferentes métodos para perïodos de pentadas, observa-se que o valor de $\overline{\mathrm{ET}}_{\mathrm{ol2}} \mathrm{x}$ Radiação Solar $(r=0,934)$ foi o que apresentou maior grau de correlação, resultado este que vai de encontro ao esperado de que a melhor correlação seria com o tanque Classe A onde obteve-se um $r=0,893$, devendo atribuir-se isso ao erro experimental ocorrido talvez pelo pequeno número de dados analisado. Os demais re sultados. obtidos para os métodos restantes apresentaram pela ordem o seguinte grau de correlação: Penman modificado $(r=0,877)$, Penman convencional $(r=0,830)$ e Thorthwaite $(r=0,513)$. De acordo com o teste F, todos os métodos apresentaram-se como significativos ao ni vel de $1 \%$, exceto o de Thornthwaite (5\%). Por estes resultados.e pe. 
la dispersão dos pontos em torno das retas de regressão (vide Figura B), acreditamos como viável para estimativas de evapotranspiração potencial qualquer um destes métodos, à exceção do. método de Thornthwaite, que como demonstra a prática, é utilizado apenas para fins de obtenção de indices climáticos, em estimativas mensais. 


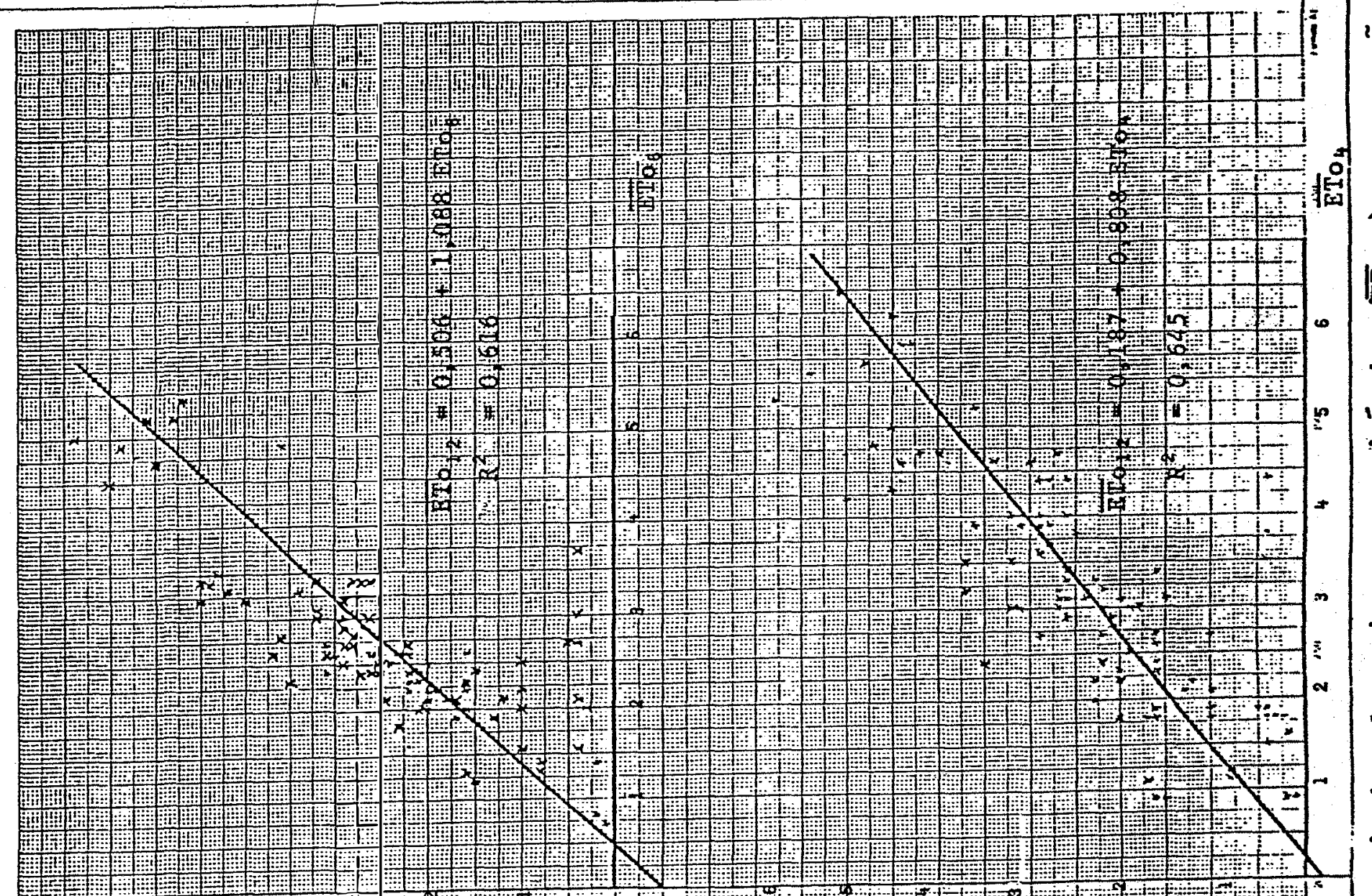

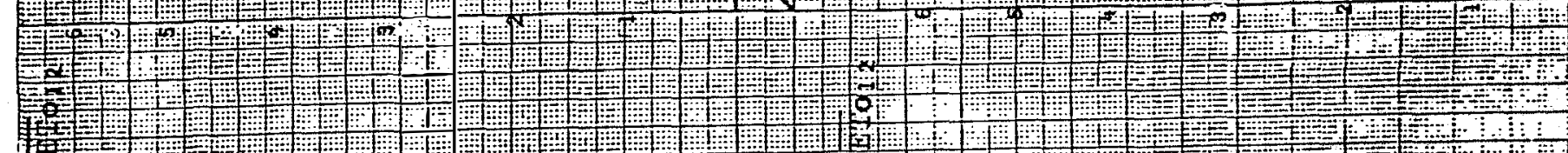

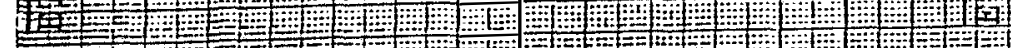

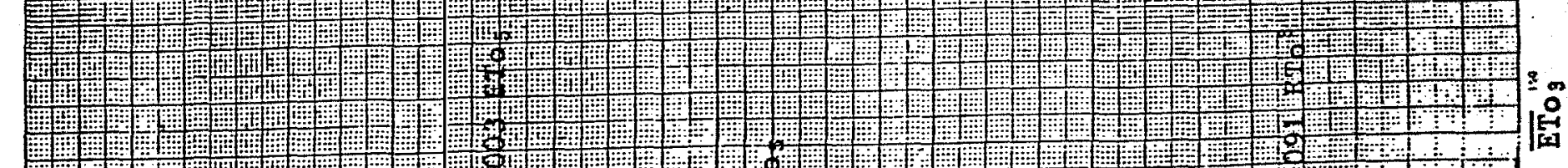
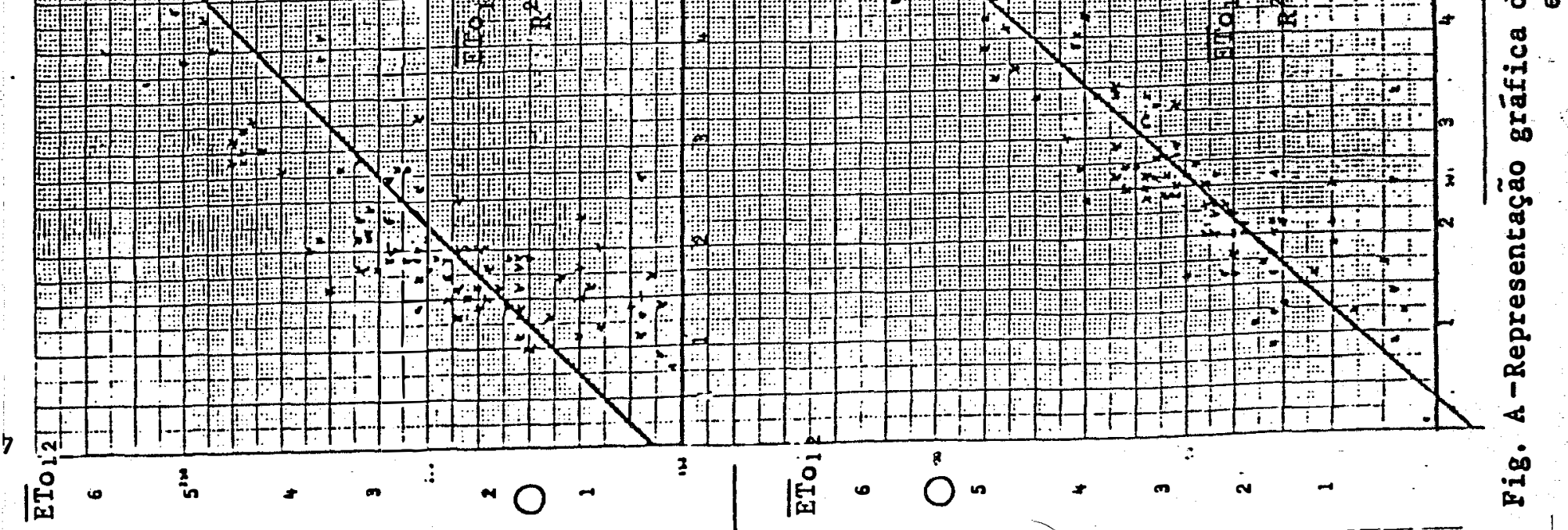


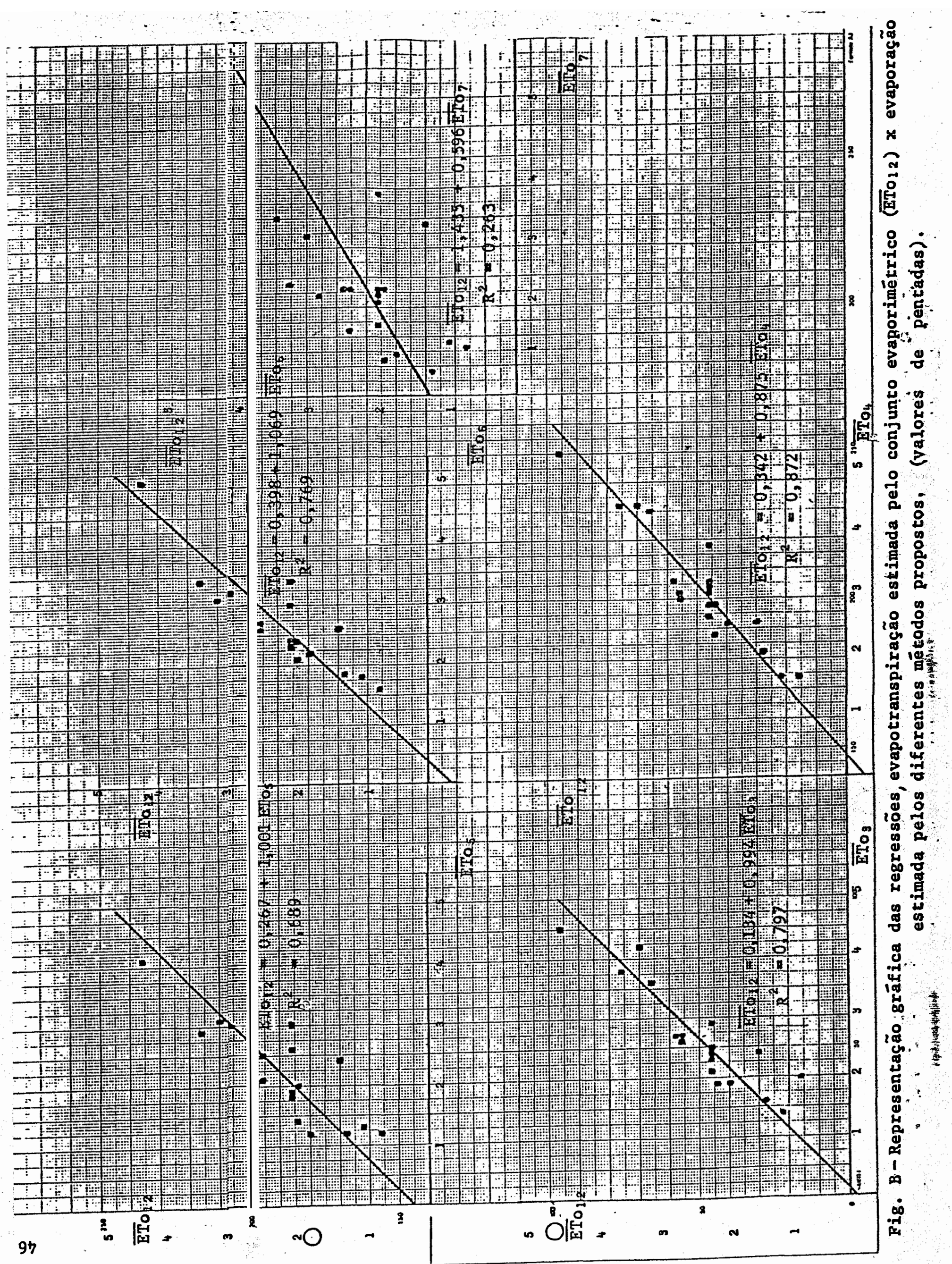


47.

\section{CONCLUSOES}

7.1. - A análise preliminar dos dados obtidos em dias de medidas simultâneas de evaporação realizadas pelo Tanque Classe A modificado e pelo Tanque Classe A nos permite concluir que:

7.1.1. - $\bar{E}$ perfèitamente viável a utilizáção do sistema de medida de evaporação apresentado em substituição ao processo mi cro métrico convencional, pois o sistema de medida utilizado no Tanque Classe A modificado nos sugere as seguintes vantagens sobre o processo convenciona1:

a) Permite a leitura da evaporação em dias de chuva, mesmo naqueles nos quais ocorre o transbordamente do tanque convenciona1; 
b) As leituras sendo realizadas em uma escala linear simples, deverão minimizar os frequentes erros operacionais detectados na prätica, devido ao baixo nível operacional requerido.

7.2. - 0 confronto entre métodos de estimativa de evapotranspiração, tendo como padrão o método do Tanque Classe A, operado pelo conjunto evaporimétrico, nos demonstrou que:

7.2.1 - Os diferentes mêtodos utilizados no trabalho, para estimar evapotranspiração potencial, quando confrontados com o padrão proposto, apresentam menor desvio e melhor correlação para valores de pentadas, do que para valores diārios.

7.2.2 - As melhores concordâncias dos resultados de estimativa de evapotranspiração potencial calculados por meio de fórmulas com o do Tanque Classe A modificado foram, pela ordem: método da radiação solar, Penman simplificado e Penman convencional, com níveis de significância semelhantes. 0 método de Thornthwai te discordou acentuadamente, indicando não ser recomendada sua utilização,pa ra períodos de 5 dias. 
49.

8 - BIBLIOGRAFIA

ALBERIO, I.A. de S., 1979. Estudo sobre modificações introduzidas no tanque Classe A e no método de Penman. Piracicaba, ESALQ/USP, 91 p. (Dissertação de Mestrado).

ASSIS, F.N. de, 1978. 0 uso do evapotranspirômetro no estudo de al. gumas relações entre a evapotranspiração medida e estimada. Piracicaba, ESALQ/USP. 73 p. (Dissertação de Mestrado).

ASSIS, F.N. de e H.J. VIETRA, 1981. Estimativa da evaporação do tan que Classe A durante o ciclo de crescimento das culturas de verão em Pelotas-RS. In: Resumos Ampliados:dos Trabalhos apresen tados nas Sessões Técnicas do II CONGRESSO BRASILEIRO DE AGROMETEOROLOGIA. Pelotas. pp. 94-96.

BERLATO, M.A. e L.C.B. MOLION, 1981. Evaporação e Evapotranspiração. Boletim Técnico. IPAGRo, nọ 7. p. 95. 
BROWN, P.L. e A.L. HALLSTED, 1952. Comparison of evaporation data from standard weather bureau and plant industry type evaporation pans. Agrronomy Journal, Wash, D.C. 44(2): 100-101.

CAMARGO, A.P. de, 1961. Contribuição para a determinação de evapotranspiração potencial no Estado de São Paulo. Piracicaba, ESALQ/ USP. 49 p. (Tese de Doutoramento).

CAMPBELL, R.B. e C.J. PHENE, 1976. Estimating potential evapotrans piration from screened pan evaporation. Agricultural Meteorology, 16: 343-352.

CHANG, H.; H.S. WANG e F.W. HO, 1968. The effect of different pan ratio for controlling irrigation of sugarcane in Taiwan. 13 Th Congr. ISSCT. Tainan. Proc, 13: 652-663.

CHAPAS, L.C. e A.R. REES, 1963. Evaporation and evapotranspiration in Southern Nigeria. Quant. J.R. Met. Soc. p. 313-319.

CRUCIANI, D.E., 1972. Balanço hídrico em solo cultivado com cana-de-açúcar, utilização do método da moderação de neutrons. Boletim Científico, CENA (BC-006). 35 p.

DALE, R.F. e K.L. SCHEERINGA, 1977. The effect of soil moisture on pan evaporation. Agricultural Meteorology; 18: 463-474.

DENMEAD, 0.T. e R.H. SHAW, 1959. Evapotranspiration in relation to the development of the corn crop. Agran. J. 51 (12): 725-726.

DOSS, B.D.; O.L. BENNETT e D.A. ASHLEY, 1974. Evapotranspiration by Irrigated Corn. Soil Sci.: 54(6): 497-49.8. 
EARLY, A.C. e R.P. GREGORIO, 1971. Consumptive use of Water by Sugarcane in the Philippines. 14 Th Congr. ISSCT. Lousiana. Proc. 14: $813-826$.

EKERN, P.C., 1966. Evapotranspiration by Bermuda-grass Sod (Cynodon ; dactyZon, L. Pers.), in Hawaii. Agronomy Journal. Madison, 58(4): 387-390.

EMBRAPA, 1978. Centro Nacional de Pesquisa de Arroz e Feijão, Goiânia. Relatório de Pesquisas com Feijão, 1976-77. p. 70 (Mimeografado.

ENCARNAÇÃo, C.R.F. de, 1980. Estudo da Demanda de Āgua do Feijoeiro (Phaseolus vulgaris, L.) Var. Goiano Precoce. Piracicaba, ESALQ/ USP. 62 p. (Dissertação de Mestrado).

EVANS, G.N., 1971. Evaporation from Rice at Griffith. New South Wales. Agr. Meteorol. 8(2): 117-127.

FAO, 1975. Crop Water Requirements. J. DOORENBOS e W.0. SMITT. Irrigation and Drainage Paper 24. Rome. p. 179.

FAO, 1976. Agro-Meteorological Field Stations. J. DOORENBBOS. Irrigation and Drainage Paper 27. Rome. p. 94.

FAO, 197.9. Yield Response to Water. J. DOORENBOS e A.H. KASSANS. Irrigation and Drainage Paper 33. Rome. p. 193.

FERREIRA, W.A., 1972. Utilização da Evaporação "Piche" na Estimativa da Evapotranspiração Potencial. Botucatu, F.C.M.B.B. p. 67. (Tese de Doutoramento). 
FRITSCHEN, L.J. e R.H. SHAW, 1961. Evapotranspiration for corn as related to pan evaporation. Agron. J. 53(3): 149-150.

FUCHS, M. e G. STANHILL, 1963. The use of Class A pan evaporation data to estimate the irrigation water requirements of the cotton crop. J.Agric. Res. Israel, 13(2): 63-78.

FUCHS, M.; I. HAUSENBERG e G. STANHILL; 1964. A field test of the control of cotton irrigation practice from Classe A pan data. J. Agric. Rés. Israel, 14: 237-239.

GOLDBERG, S.D.; B. GORNAT e D. SADAN, 1966. Relation between water consumption of planuts and Class A pan evaporation during the growing season. Soil Sci. 104(4): 289-296.

HANSON, C.L. e F. RANZI, 1977. Class A pan evaporation as affected by she ter and daily prediction equation. Agricultural Meteorology. Amsterdan, 18: 27-35.

JENSEN, M.C. e H.R. HAISE, 1963. Estimating evapotranspiration from solar radiation. J. Irrig. Drain. Dice. A, Soc. Cice. Engrs. 89 (IR4): $15-41$.

JONES, C.A., 1980. A review of evapotranspiration studies in irrigated sugar cane in Hawai. Publication of the Experiment Station. Hawaiian Sugar Planters Association 59(9): 195-214.

JUNIOR, A.L., 1978. Determinação do coeficiente de cultura (kc) para feijão (Phaseolus vulgaris L.) pelo método do balanço hídrico. Piracicaba, ESALQ/USP. 59 p. (Dissertação de Mestrado). 
KALMA, J.D. e G. STANHILL, 1969. Transpiration, evaporation and deep drainage losses from an orange plantation. J. Agric. Res. Israel, 1.9(1): $11-24$.

KRUTMAN, S., 1963. Método para indicação de regas. Evapotranspiração da Cana e Evaporação. IPEANE, Recife, 22: 1-18.

LOMAS, J. e E. SCHIESINGER, 1970, The influence of a windbreak on evapotranspiration. Agr. Meteorol. 8: 107-115.

MATZANUER, R.; S.L. WESTPHALEN; H. BERGAMASCHI e V.R. SUTILI, 1981. Evapotranspiração do milho (Zea mays L.) e sua relação com a evaporação do tanque Classe A. In: RESUMOS AMPLIADOS DOS TRABALHOS APRESENTADOS NAS SESSŌES TÉCNICAS DO II CONGRESSO BRASILEIRO DE AGROMETEOROLOGIA. Pelotas, p, 11-16.

OLIVEIRA, A.S., 1971. Estudos comparatịvos da evaporação potencial estimada por tanques e pelo método de Penman. Piracicaba, ESALQ/ USP. 113 p. (Tese de Livre Docência).

OMETTO, J.C., 1968. Estudos das relações entre: Rediação Solar Global, Radiação Lỉquida e Insolação. Piracícaba, ESALQ/USP : 64 p. (Tese de Doutoramento).

PENMAN, H.L,, 1948. Natural evaporation from open water, bare soil and grass. Proc. Roy. Soc. of London, Ser, A, 193: 120-145.

PENMAN, H.L., 1956. Evaporation: an introductory survey. Neth. J.Agric. Sci. 4(1): 9-29.

SCARDUA, R., 1970. Evapotranspiração real da cultura do mịtho como base aos projetos de irrigação. Piracicaba, ESALQ/USP. 160 p. (Tese de Doutoramento). 
SILVA, W.J. da; G.C. SEDIYAMA e D.T.C.S. BERNARDO, 1981. Estimativa da evaporação potencial em condições de campo, usando tanque "Classe A" modificado. In: RESUMOS AMPLIADOS DOS TRABALHOS APRE SENTADOS NAS SESSÕES TÉCNICAS DO II CONGRESSO BRASILEIRO DE AGRO METEOROLOGIA. Pelotas, p. 119-121.

STANHILL, G., 1958. An irrigation gange for conmercial use in field and glasshouse practice. J.Agric. Engr. Res., Wellesbourn, $\underline{3}(4)$ : 292.

STANHILL, G., 1961. A comparison of methods of calculating potential evapotranspiration from climatic data. J. Agric. Res. Israel $11(3 / 4)$ : 159-171.

STANHILL, G., 1962. The use of Piche evaporimeter in the calculation of evaporation. Quart. J. Roy. Met. Soc. 88: 80-82.

TANNER, C.B., 1968. Evaporation of water from plants and soil. In: KOZLOWAKI, T.T. (ed.) Water deficits and plant growth (vol, 1). Nova York, Academic Pres. p. 73-76.

THOMPSON, G.D., 1965. The relationship of potential evapotranspiration of sugarcane to environmental factors. $12 \mathrm{Th}$. Congress ISSCT. Puerto Rico, 12: 3-9.

THOMPSON, G.D. e J.P. BOYCE, 1967. Daily measurement of potential evapotranspiration from fully canopied sugar cane. Agric. Meteorol. 4: 267-279.

THORNTHWAITE, C.W., 19.48: An approach toward a rational classification of climate. Geographical Review. Nova York, 38: 55-94. 
THORNTHWATE, C.W. e J.R. MATHER, 1955. The water balance. Publ. in Climatology 8(1) Lab. of Climatology. Centerton, N.J.

TOVEY, R.; J.S. SPENCER E D.C. MUCKEL, 1969.. Turfgrass evapotranspiration. Agronomy J. 61(6): 863-867.

VILLA NOVA, N.A:, 1967. A estimativa da evaporação potencial no Es tado de São Paulo. Piracicaba, ESALQ/USP. 66 p. (Tese de Douto ramento).

VILLA NOVA, N.A. e J.C. OMETTO, 1981. Adaptação e simplificação do método de Penman às condições climáticas do Estado de São Paulo. Travalho apresentado no IV SIMPÓSIO BRASILEIRO DE HIDROLOGIA e RE CURSOS HIDRICOS. Fortaleza.

WARTENA, L. e A.J.W. BORGHORST, 1960. The energy balance of an evaporation pan and the measurement of the reflectivity of its bot- . tons. Quartely Journal of the Royal Meteorological Society, 87(372): 245-249.

W.M.O., 1966. Measurement and estimation of evaporation and evapotranspiration. Technical note 83. p. 121 . 


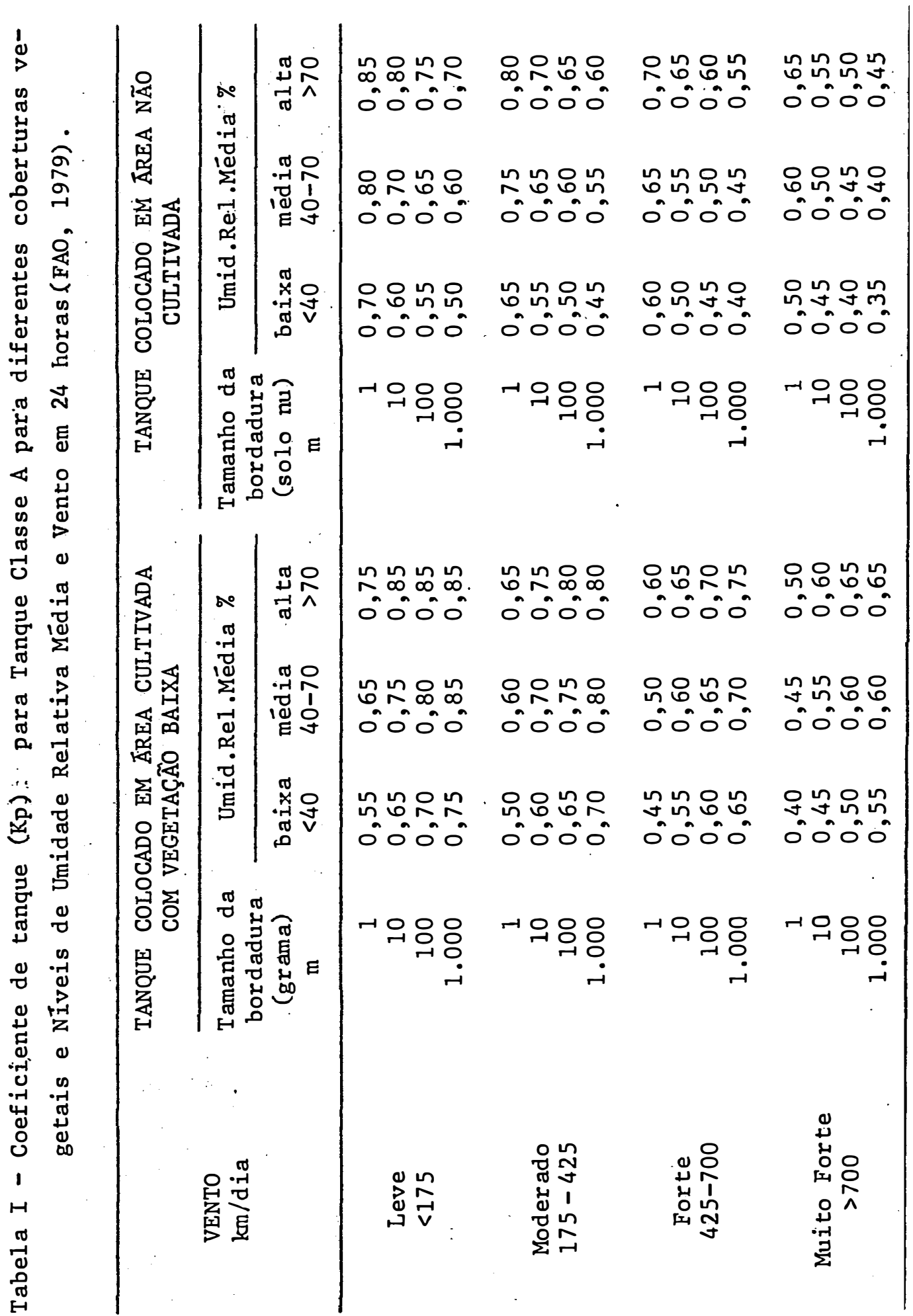




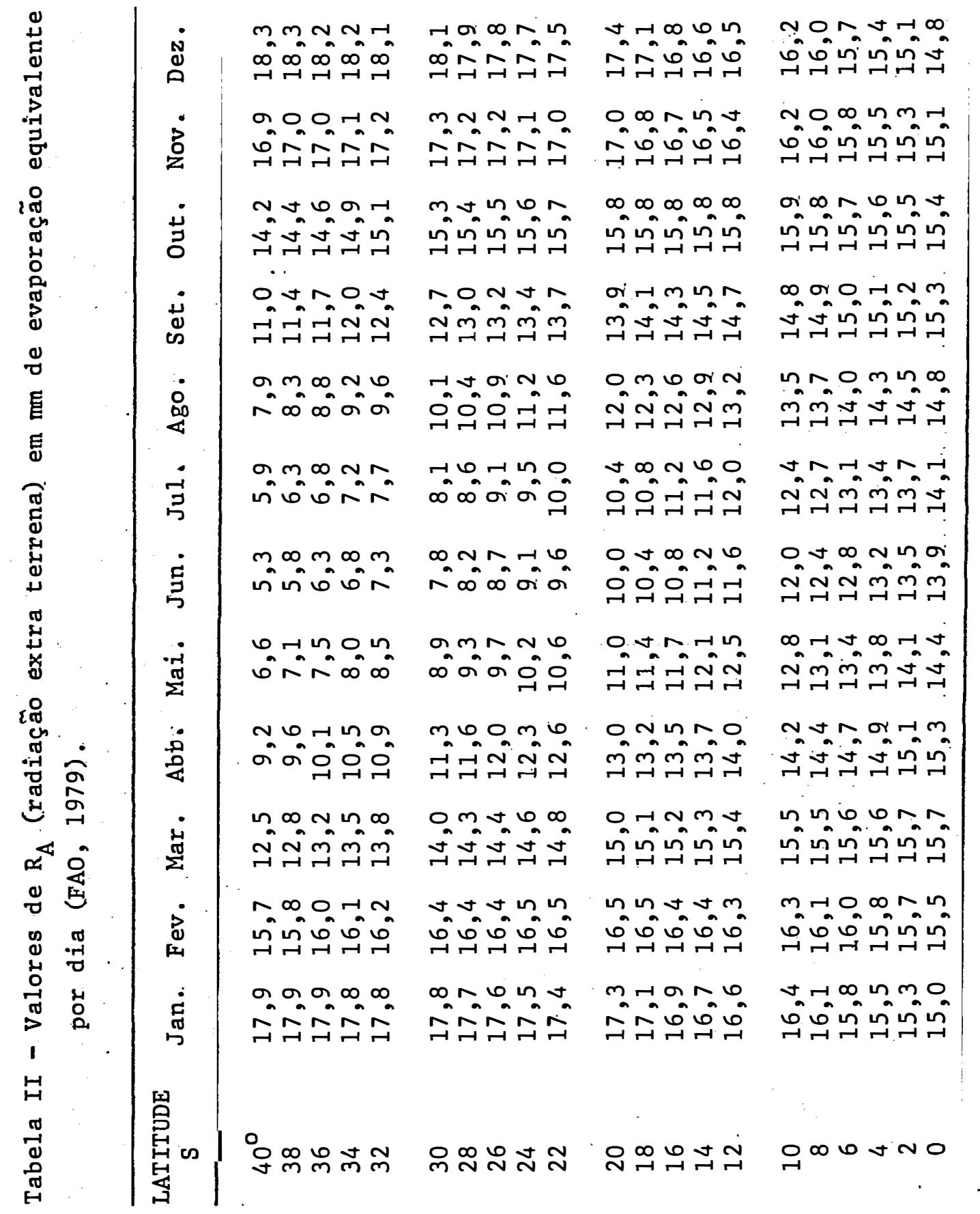


Tabela III - Valores do fator de ponderação (W) para o efeito da ra diação solar ET a diferentes temperaturas e altitudes (FAO, 1979).

\begin{tabular}{|c|c|c|c|c|c|}
\hline \multirow{2}{*}{$\begin{array}{l}\text { TEMPERATURA } \\
{ }^{{ }^{C} \mathrm{C}}\end{array}$} & \multicolumn{5}{|c|}{$W$ a altitude (m) $\ldots$} \\
\hline & 0 & 500 & 1.000 & 2.000 & 3,000 \\
\hline 2 & 0,43 & 0,45 & 0,46 & 0,49 & 0,52 \\
\hline 4 & 0,46 & 0,48 & 0,49 & 0,52 & 0,55 \\
\hline 6 & 0,49 & 0,51 & 0,52 & 0,55 & 0,58 \\
\hline 8 & 0,52 & 0,54 & 0,55 & 0,58 & 0,61 \\
\hline 10 & 0,55 & 0,57 & 0,58 & 0,61 & 0,64 \\
\hline 12 & 0,58 & 0,60 & 0,61 & 0,64 & 0,66 \\
\hline 14 & 0,61 & 0,62 & 0,64 & 0,66 & 0,69 \\
\hline 16 & 0,64 & $0,65^{\circ}$ & 0,66 & 0,69 & 0,71 \\
\hline 18 & 0,66 & 0,67 & 0,69 & 0,71 & 0,73 \\
\hline 20 & 0,69 & 0,70 & 0,71 & 0,73 & 0,75 \\
\hline 22 & 0,71 & 0,72 & 0,73 & 0,75 & 0,77 \\
\hline 24 & 0,73 & 0,74 & 0,75 & 0,77 & 0,79 \\
\hline 26 & 0,75 & 0,76 & 0,77 & 0,79 & 0,81 \\
\hline 28 & 0,77 & 0,78 & 0,79 & 0,81 & 0,82 \\
\hline 30 & 0,78 & 0,79 & 0,80 & 0,82 & 0,84 \\
\hline 32 & 0,80 & 0,81 & 0,82 & 0,84 & 0,85 \\
\hline 34 & 0,82 & 0,82 & 0,83 & 0,85 & 0,86 \\
\hline 36 & 0,83 & 0,84 & 0,85 & 0,86 & 0,88 \\
\hline 38 & 0,84 & 0,85 & 0,86 & 0,87 & $0 ; 88$ \\
\hline 40 & 0,85 & 0,86 & 0,87 & 0,88 & 0,89 \\
\hline
\end{tabular}


Tabela IV-A - Valores de evapotranspiração potencial diāria estimados em função da temperatura média diāria e temperatu ra média anual.

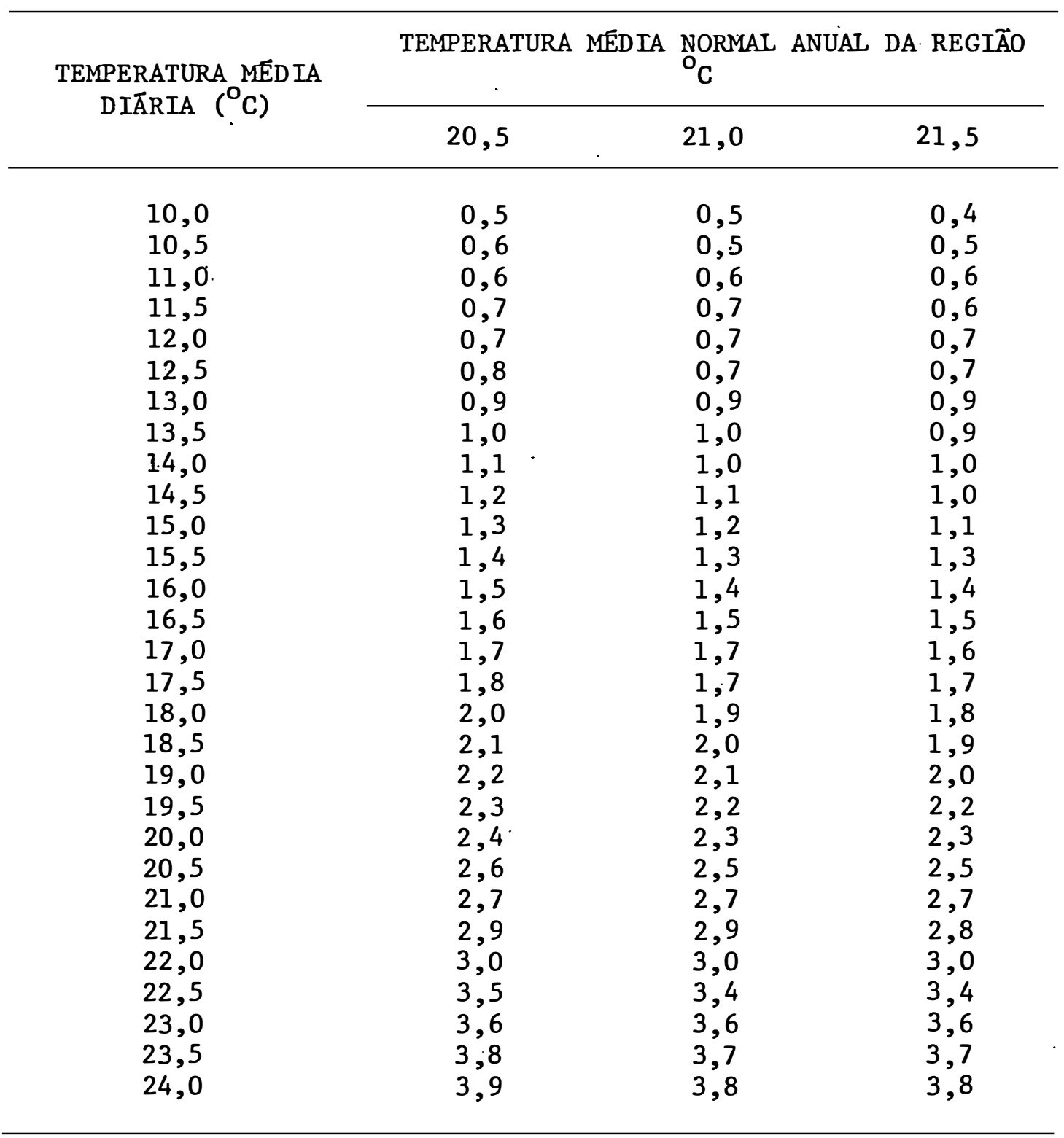


Tabela IV-B - Valores do fator de correção diārio f́, para latitude de $22^{\circ} 43^{\prime}$, ao longo do ano.

\begin{tabular}{lc}
\hline MESES & FATOR DE AJUSTE (f) \\
\hline Janeiro & 1,116 \\
Fevereiro & 1,075 \\
Março & 1,016 \\
Abril & 0,96 \\
Maio & 0,913 \\
Junho & 0,890 \\
Julho & 0,900 \\
Agosto & 0,948 \\
Setembro & 1,00 \\
Outubro & 1,055 \\
Novembro & 1,110 \\
Dezembro & 1,132 \\
\hline
\end{tabular}


Tabela V - Valores de $\Delta / \gamma$ entre 1 e $40^{\circ} \mathrm{C}$ (VILA NOVA, 1967).

\begin{tabular}{|c|c|c|c|c|}
\hline$t$ & & $\Delta / \gamma$ & $t$ & $\Delta / \gamma$ \\
\hline 1 & & 0,6 & 21 & 2,2 \\
\hline 2 & & 0,8 & 22 & 2,4 \\
\hline 3 & & 0,8 & 23 & 2,6 \\
\hline 4 & . & 0,8 & 24 & 2,6 \\
\hline 5 & & 1,0 & 25 & 2,8 \\
\hline 6 & & 1,0 & 26 & 3,0 \\
\hline 7 & & 1,2 & 27 & 3,2 \\
\hline 8 & & 1,2 & 28 & 3,2 \\
\hline 9 & & 1,2 & 29 & 3,6 \\
\hline 10 & & 1,2 & 30 & 3,8 \\
\hline 11. & & 1,4 & 31 & 4,0 \\
\hline 12 & & 1,4 & 32 & 4,2 \\
\hline 13 & & 1,6 & 33 & 4,2 \\
\hline 14 & & 1,6 & 34 & 4,4 \\
\hline 15 & & 1,6 & 35 & 4,6 \\
\hline 16 & & 1,8 & . 36 & 5,2 \\
\hline 17 & & 1,8 & 37 & 5,2 \\
\hline 18 & & 2,0 & 38 & 5,4 \\
\hline 19 & & 2,0 & 39 & 5,6 \\
\hline 20 & & 2,0 & 40 & 5,8 \\
\hline
\end{tabular}


Quadro I - Comparações entre medidas simultâneas de evaporação, obtidas no tanque $A$ e no tanque medidor. $\Delta h_{1}=$ medida no tanque $\mathrm{A}$ (micrômetro); $\Delta \mathrm{h}_{3}=$ mèdida no tanque medidor (mm de altura/mm de evaporação); $\mathrm{S}_{1} / \mathrm{S}_{3}=$ relação entre as áreas reais dos tanques $\mathrm{A}_{1} / \mathrm{A}_{3}$.

\begin{tabular}{|c|c|c|c|c|c|c|c|}
\hline \multicolumn{3}{|c|}{ MICROMETRO } & \multicolumn{3}{|c|}{ TANQUE MEDIDOR } & \multirow{2}{*}{$\frac{\mathrm{S}_{1}}{\mathrm{~S}_{3}}=\frac{\Delta \mathrm{h}_{3}}{\Delta \mathrm{h}_{1}}$} & \multirow[b]{2}{*}{$\begin{array}{c}\Delta \mathrm{h}_{3}=\Delta \mathrm{h}_{1} \\
(\mathrm{~mm})\end{array}$} \\
\hline $\begin{array}{l}\text { Inicial } \\
\text { (mim) }\end{array}$ & $\underset{(\mathrm{mm})}{\text { Final }}$ & $\stackrel{\Delta \mathrm{h}_{1}}{(\mathrm{~mm})}$. & $\underset{(m n)}{\text { Inicial }}$ & $\begin{array}{c}\text { Final } \\
\text { (mm) }\end{array}$ & $\begin{array}{l}\Delta \mathrm{h}_{3} \\
(\mathrm{~mm})\end{array}$ & & \\
\hline 49,80 & 58,55 & 8,75 & 0 & 176 & $176 / 8,80$ & $1: 20,1$ & $+0,05$ \\
\hline 58,55 & 67,23 & 8,70 & 0 & 177 & $177 / 8,85$ & $1: 20,3$ & $+0,15$ \\
\hline 31,64 & 40,42 & 8,79 & 0 & 177 & $177 / 8,85$ & $1: 20,2$ & 0,06 \\
\hline 40,42 & 49,11 & 8,69 & 0 & 176 & $176 / 8,80$ & $1: 20,2$ & 0,11 \\
\hline 57,60 & 66,36 & 8,76 & 0 & 176 & $176 / 8,80$ & $1: 20,1$ & 0,04 \\
\hline MEEDIAS & & & & & & $1: 20,2$ & 0,08 \\
\hline
\end{tabular}

\begin{tabular}{|c|c|c|c|c|c|c|c|}
\hline \multicolumn{3}{|c|}{ MICROMETRO } & \multicolumn{3}{|c|}{ TANQUE MEDIDOR } & \multirow{2}{*}{$\frac{\mathrm{S}_{1}}{\mathrm{~S}_{3}}=\frac{\Delta \mathrm{h}_{3}}{\Delta \mathrm{h}_{1}}$} & \multirow[b]{2}{*}{$\begin{array}{c}\Delta \mathrm{h}_{3}-\Delta \mathrm{h}_{1} \\
\quad(\mathrm{~mm})\end{array}$} \\
\hline $\begin{array}{l}\text { Inicial } \\
\text { (mm) }\end{array}$ & $\begin{array}{c}\text { Final } \\
\text { (mm) }\end{array}$ & $\begin{array}{l}\Delta \mathrm{h}_{1} \\
(\mathrm{~mm})\end{array}$ & $\begin{array}{c}\text { Inicial } \\
\quad(\mathrm{mm})\end{array}$ & $\begin{array}{c}\text { Final } \\
(\mathrm{mm})\end{array}$ & $\begin{array}{l}\Delta \mathrm{h}_{3} \\
(\mathrm{~mm})\end{array}$ & & \\
\hline 50,64 & 59,33 & 8,69 & 0 & 177 & $177 / 8,85$ & $1: 20,4$ & 0,16 \\
\hline 59,33 & 68,18 & 8,85 & 0 & 177 & $177 / 8,85$ & $1: 20,0$ & 0,00 \\
\hline 54,14 & 62,81 & 8,67 & 0 & 177 & $177 / 8,85$ & $1: 20,4$ & 0,18 \\
\hline 25,45 & 34,04 & 8,59 & 0 & 176 & $176 / 8,80$ & $1: 20,5$ & 0,21 \\
\hline 34,04 & 42,68 & 8,64 & 0 & 177 & $177 / 8,85$ & $1: 20,5$ & 0,21 \\
\hline MEDIAS & & & & & & $1: 20,4$ & 0,15 \\
\hline
\end{tabular}


Quadro II - Valores simultâneos medidos de evaporação de tanque (mm/ dia), no tanque padrão $A\left(E_{p}\right)$, tanque modificado $1\left(E_{1}\right)$, - tanque modificado $2\left(E_{2}\right)$ e média de $E_{2}$ e $E_{2}\left(\bar{E}_{21}\right)$ em dias sem chuva. Piracicaba, SP. 1981.

\begin{tabular}{ccccc} 
& \multicolumn{5}{c}{ Março } & $\mathrm{E}_{2}$ & $\overline{\mathrm{E}}_{12}$ \\
\hline DIAS & $\mathrm{E}_{\mathrm{P}}$ & $\mathrm{E}_{1}$ & 5,2 & 4,2 \\
\hline 20 & 4,8 & 3,3 & 6,6 & 6,7 \\
21 & 5,5 & 6,9 & 7,2 & 7,4 \\
22 & 6,9 & 7,6 & 6,0 & 6,2 \\
23 & 5,6 & 6,3 & 5,5 & 5,7 \\
24 & 5,2 & 5,9 & 5,1 & 5,9 \\
25 & 5,5 & 6,7 & 6,1 & 6,3 \\
26 & 5,8 & 6,5 & 4,6 & 4,5 \\
30 & 4,9 & 4,4 & 6,0 & 5,8 \\
31 & 5,8 & 5,7 & &
\end{tabular}

$\therefore$ Abril

\begin{tabular}{ccccc}
\hline DIAS & $\mathrm{E}_{\mathrm{p}}$ & $\mathrm{E}_{1}$ & $\mathrm{E}_{2}$ & $\overline{\mathrm{E}}_{12}$ \\
\hline 1 & 5,7 & 5,2 & 6,1 & 5,6 \\
2 & 4,9 & 6,0 & 5,3 & 5,6 \\
5 & 4,3 & 3,4 & 4,6 & 4,0 \\
6 & 5,2 & 5,5 & 5,3 & 5,4 \\
7 & 4,5 & 5,1 & 5,7 & 5,4 \\
8 & 4,7 & 5,3 & 5,1 & 5,2 \\
9 & 5,7 & 5,2 & 5,7 & 5,5 \\
10 & 5,5 & 5,3 & 5,7 & 5,5 \\
11 & 4,2 & 4,3 & 4,2 & 4,3 \\
12 & 4,3 & 5,1 & 4,9 & 5,0 \\
13 & 4,1 & 3,3 & 3,7 & 3,5 \\
14 & 3,5 & 2,7 & 3,2 & 3,5 \\
19 & 3,5 & 2,9 & 3,8 & 3,4 \\
21 & 3,3 & 3,5 & 3,4 & 3,5 \\
22 & 4,0 & 3,9 & 3,4 & 3,6 \\
23 & 1,4 & 1,1 & 1,0 & 1,1 \\
25 & 3,3 & 3,6 & 2,8 & 3,2 \\
26 & 4,2 & 3,5 & 3,0 & 3,3 \\
28 & 1,4 & 1,2 & 0,9 & 1,1 \\
29 & 2,3 & 1,9 & 2,1 & 2,0 \\
30 & 3,8 & 3,6 & 3,4 & 3,5 \\
\hline
\end{tabular}


Quadro II - (Continuação).

Maio

\begin{tabular}{cclll}
\hline DIAS & $\mathrm{E}_{\mathrm{p}}$ & $\mathrm{E}_{1}$ & $\mathrm{E}_{2}$ & $\overline{\mathrm{E}}_{12}$ \\
\hline 1 & 2,0 & 2,4 & 3,7 & 3,1 \\
2 & 2,7 & 3,1 & 2,1 & 2,6 \\
4 & 2,7 & 2,8 & 2,6 & 2,7 \\
5 & 2,5 & 2,0 & 2,6 & 2,3 \\
6 & 3,2 & 2,9 & 3,2 & 3,1 \\
7 & 3,1 & 4,0 & 2,4 & 3,2 \\
8 & 3,2 & 2,2 & 3,4 & 2,8 \\
9 & 3,4 & 2,8 & 3,3 & 3,1 \\
10 & 3,4 & 4,7 & 4,1 & 4,4 \\
11 & 3,4 & 4,0 & 3,8 & 3,9 \\
12 & 3,2 & 2,5 & 3,1 & 2,8 \\
13 & 3,3 & 3,3 & 3,7 & 3,5 \\
14 & 4,3 & 3,3 & 4,1 & 3,7 \\
15 & 3,1 & 3,0 & 3,5 & 3,3 \\
16 & 1,9 & 2,8 & 1,9 & 2,4 \\
17 & 3,7 & 3,3 & 4,8 & 4,1 \\
19 & 2,9 & 2,4 & 2,8 & 2,6 \\
20 & 2,4 & 1,5 & 2,3 & 1,9 \\
21 & 2,4 & 1,8 & 1,9 & 1,8 \\
22 & 3,8 & 5,0 & 4,2 & 4,6 \\
23 & 3,0 & 3,6 & 3,3 & 3,5 \\
24 & 3,1 & 4,9 & 2,9 & 3,9 \\
25 & 3,2 & 3,0 & 3,2 & 3,1 \\
26 & 3,3 & 4,5 & 3,0 & 3,7 \\
27 & 2,6 & 1,1 & 2,6 & 1,8 \\
28 & 2,3 & 2,5 & 2,9 & 2,7 \\
29 & 2,9 & 4,0 & 3,4 & 3,7 \\
30 & 3,5 & 3,4 & 3,5 & 3,5 \\
31 & 3,1 & 4,0 & 3,2 & 3,6 \\
& & & & \\
\hline
\end{tabular}


Quadro II - (Continuação).

Junho

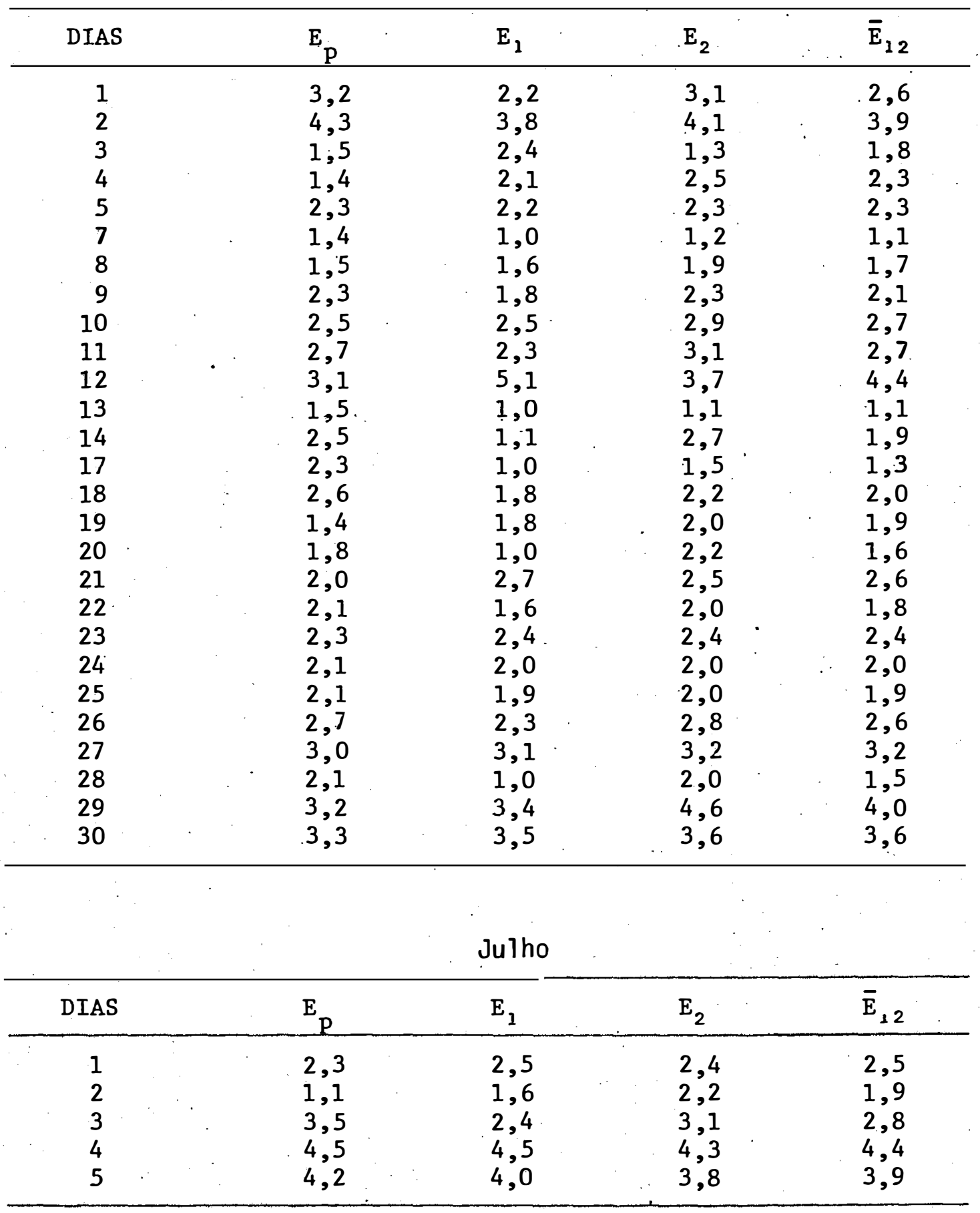


Quadro III - Valores simultâneos acumulados (mm/3 dias) de evaporação de tanque, no tanque padrão $A\left(E_{p}^{\prime}\right)$, tanque modificado $1\left(E_{1}^{\prime}\right)$, tanque modificado $2\left(E_{2}^{\prime}\right)$ e média de $E_{1}^{\prime}$ e $E_{\cdot}^{\prime}\left(\bar{E}_{2}^{\prime}\right)$, em dias sem chuva. Piracicaba, SP, 1981.

\begin{tabular}{lcccc}
\hline DIAS & \multicolumn{5}{c}{ Março } & \\
\hline $20-22$ & $\mathrm{E}_{\mathrm{P}}^{\prime}$ & $\mathrm{E}_{1}$ & $\mathrm{E}_{2}$ & $\overline{\mathrm{E}}_{12}$ \\
\hline $23-25$ & 17,2 & 17,8 & 19,0 & 18,3 \\
$24-26$ & 16,3 & 18,9 & 16,6 & 17,8 \\
$30-01 / 04$ & 16,5 & 19,1 & 16,7 & 17,9 \\
\hline
\end{tabular}

Abri1

\begin{tabular}{ccccc}
\hline DIAS & $\mathrm{E}_{\mathrm{p}}^{\prime}$ & $\mathrm{E}_{1}$ & $\mathrm{E}_{2}$ & $\overline{\mathrm{E}}_{12}$ \\
\hline $31 / 03-2$ & 16,4 & 17,0 & 17,4 & 17,0 \\
$5-7$ & 14,0 & 14,0 & 15,6 & 14,8 \\
$8-10$ & 15,9 & 15,8 & 16,5 & 16,2 \\
$11-13$ & 12,6 & 12,7 & 12,8 & 12,8 \\
$12-14$ & 11,9 & 11,1 & 11,8 & 12,0 \\
$21-23$ & 8,7 & 8,5 & 7,8 & 8,2 \\
$28-30$ & 7,5 & 6,7 & 6,4 & 6,6 \\
\hline
\end{tabular}

Maio

\begin{tabular}{crrrr}
\hline DIAS & $E_{p}^{\prime}$ & $E_{1}$ & $E_{2}$ & $\bar{E}_{12}$ \\
\hline $30 / 04-2$ & 8,5 & 9,1 & 9,2 & 9,2 \\
$4-6$ & 8,4 & 7,7 & 8,4 & 8,1 \\
$7-9$ & 9,7 & 9,0 & 9,1 & 9,1 \\
$10-12$ & 10,0 & 11,2 & 11,0 & 11,1 \\
$13-15$ & 10,7 & 9,6 & 11,3 & 10,5 \\
$16-18$ & 8,7 & 10,3 & 9,7 & 10,1 \\
$19-21$ & 7,7 & 5,7 & 7,0 & 6,3 \\
$22-24$ & 9,9 & 13,5 & 10,4 & 12,0 \\
$25-27$ & 9,1 & 8,6 & 8,8 & 8,6 \\
$28-30$ & 8,7 & 9,9 & 9,8 & 9,9 \\
\hline
\end{tabular}


Quadro III - (Continuação).

Junho

\begin{tabular}{crrrr}
\hline DIAS & $E_{P}^{\prime}$ & $E_{1}^{\prime}$ & $E_{2}^{\prime}$ & $\bar{E}_{12}^{\prime}$ \\
\hline $31 / 05-2$ & 10,6 & 10,0 & 10,4 & 10,1 \\
$3-5$ & 5,2 & 6,7 & 6,1 & 6,4 \\
$7-9$ & 5,2 & 4,4 & 5,4 & 4,9 \\
$10-12$ & 8,3 & 9,9 & 9,7 & 9,8 \\
$12-14$ & 7,1 & 7,2 & 7,5 & 7,4 \\
$17-19$ & 6,3 & 4,6 & 5,7 & 5,2 \\
$20-22$ & 5,9 & 5,3 & 6,7 & 6,0 \\
$23-25$ & 6,5 & 6,3 & 6,4 & 6,3 \\
$26-28$ & 7,8 & 6,4 & 8,0 & 7,3 \\
$29-1 / 7$ & 8,8 & 9,4 & 10,6 & 10,1 \\
\hline
\end{tabular}

JuTho

\begin{tabular}{crrrr}
\hline DIAS & $\mathrm{E}_{\mathrm{p}}^{\prime}$ & $\mathrm{E}_{1}^{\prime}$ & $\mathrm{E}_{2}^{\prime}$ & $\overline{\mathrm{E}}_{12}^{\prime}$ \\
\hline $2-4$ & 9,1 & 8,5 & 9,6 & 9,1 \\
$3-5$ & 12,2 & 10,9 & 11,2 & 11,1 \\
\hline
\end{tabular}




\begin{tabular}{|c|c|c|c|c|c|c|}
\hline \multirow{2}{*}{ DATAS } & \multicolumn{2}{|c|}{ LEIT. MICROMETRO } & \multirow{2}{*}{$\underset{(\mathrm{mm})}{\mathrm{P}}$} & \multirow{2}{*}{$\begin{array}{l}E \\
(\mathrm{pc})\end{array}$} & \multirow{2}{*}{$\begin{array}{c}E_{1} \\
(\mathrm{~mm})\end{array}$} & \multirow{2}{*}{$\begin{array}{c}E_{2} \\
(\operatorname{mm})\end{array}$} \\
\hline & Inicial & Final & & & & \\
\hline $27 / 03$ & 65,69 & 69,66 & 5,0 & 1,03 & 1,6 & 1,3 \\
\hline $28 / 03$ & 69,66 & 69,71 & 2,1 & 2,05 & 1,5 & 1,7 \\
\hline $29 / 03$ & 69,71 & 74,42 & 7,7 & 2,99 & 1,7 & 1,3 \\
\hline $03 / 04$ & 69,52 & 75,38 & 5,1 & $-0,76$ & 1,4 & 1,6 \\
\hline $04 / 04$ & 75,38 & 79,71 & 8,4 & 4,07 & 1,4 & 1,5 \\
\hline $15 / 04$ & \multicolumn{2}{|c|}{ transbordou } & 49,2 & - & 1,1 & 1,4 \\
\hline $24 / 04$ & 79,38 & 77,34 & 5,8 & 2,44 & 1,5 & 2,6 \\
\hline $27 / 04$ & 69,90 & 74,68 & 7,7 & $2,92^{\circ}$ & 1,9 & 2,4 \\
\hline $03 / 05$ & \multicolumn{2}{|c|}{ transbordou } & 28,9 & - & 2,8 & 4,3 \\
\hline $06 / 06$ & \multicolumn{2}{|c|}{ transbordou } & 46,6 & - & 1,3 & 1,1 \\
\hline $15 / 06$ & 63,88 & 73,74 & 12,1 & 2,24 & 2,5 & 1,8 \\
\hline $16 / 06$ & 73,74 & 82,94 & 9,3 & 0,1 & 1,0 & 1,1 \\
\hline
\end{tabular}


Quadro V - Valores de evapotranspiração potencial estimada pelos di ferentes métodos considerados: evapotranspiração potencial estimada pelos tanques modificados $\left(\overline{\mathrm{ET}}_{\mathrm{O}{ }_{2}}\right)$; evapotranspiração potencial estimada pelo método do tanque $\mathbf{A}$ padrão (ET ${ }_{0}$ ); evapotranspiração estimada pelo método de radiação solar ( $\mathrm{ET}_{\mathrm{O}}$ ); evapotranspiração estimada pelo método de Penman convencional (ET ${ }_{05}$ ); evapotranspiração estimada pelo rétodo de Penman modificado (ET ${ }_{0_{6}}$ ) e evapo transpiração estimada pelo método de Thornthwaite (ET 0.7 ).

Março

\begin{tabular}{|c|c|c|c|c|c|c|}
\hline DIAS & $\overline{\mathrm{ET}}_{\mathrm{O}_{12}}$ & $\mathrm{ET}_{\mathrm{O}_{3}}$ & $\mathrm{ET}_{\mathrm{O}_{4}}$ & $\mathrm{ET}_{\mathrm{O}_{5}}$ & $\mathrm{ET}_{\mathrm{O}_{6}}$ & $\mathrm{ET}_{\mathrm{O}}$ \\
\hline $\begin{array}{l}21 \\
21 \\
22 \\
23 \\
24\end{array}$ & $\begin{array}{l}3,6 \\
5,4 \\
5,8 \\
4,8 \\
4,5\end{array}$ & $\begin{array}{l}4,0 \\
4,4 \\
5,5 \\
4,5 \\
4,2\end{array}$ & $\begin{array}{l}5,2 \\
5,6 \\
5,3 \\
5,7 \\
6,2\end{array}$ & $\begin{array}{l}4,1 \\
3,7 \\
4,0 \\
4,3 \\
4,6\end{array}$ & $\begin{array}{l}4,9 \\
4,9 \\
5,0 \\
5,2 . \\
5,5\end{array}$ & \\
\hline $\mathbf{M}$ & 4,8 & 4,5 & 5,5 & 5,1 & 5,1 & 3,0 \\
\hline $\begin{array}{l}25 \\
26 \\
27 \\
28 \\
29\end{array}$ & $\begin{array}{l}5,0 \\
5,1 \\
0,4 \\
0,5 \\
0,4\end{array}$ & $\begin{array}{l}4,7 \\
4,6 \\
0,9 \\
1,7 \\
2,5\end{array}$ & $\begin{array}{l}4,2 \\
6,4 \\
1,8 \\
1,9 \\
3,8\end{array}$ & $\begin{array}{l}3,9 \\
4,4 \\
1,8 \\
1,9 \\
3,1\end{array}$ & $\begin{array}{l}4,7 \\
5,2 \\
2,7 \\
2,7 \\
3,7\end{array}$ & \\
\hline $\mathbf{M}$ & 2,3 & 2,9 & 3,2 & 3,0 & 3,4 & 3,4 \\
\hline $\begin{array}{c}30 \\
31 \\
01 / 04 \\
02 / 04 \\
03 / 04\end{array}$ & $\begin{array}{l}3,6 \\
4,7 \\
4,5 \\
4,5 \\
0,4\end{array}$ & $\begin{array}{l}3,9 \\
4,6 \\
4,5 \\
3,9 \\
-\end{array}$ & $\begin{array}{l}4,7 \\
4,8 \\
5,0 \\
4,3 \\
4,4\end{array}$ & $\begin{array}{l}3,9 \\
4,0 \\
3,1 \\
2,9 \\
3,0\end{array}$ & $\begin{array}{l}4,9 \\
5,4 \\
3,4 \\
3,2 \\
3,0\end{array}$ & \\
\hline$M$ & 3,5 & 4,2 & 4,6 & 3,1 & 3,1 & 2,7 \\
\hline
\end{tabular}


Quadro V - (Continuação).

Abril

\begin{tabular}{|c|c|c|c|c|c|c|c|}
\hline DIAS & - & $\overline{\mathrm{ET}}_{\mathrm{O}_{12}}$ & $\mathrm{ET}_{\mathrm{O}_{3}}$ & $\mathrm{ET}_{\mathrm{O}_{4}}$ & $\mathrm{ET}_{\mathrm{O}_{5}}$ & $\mathrm{ET}_{\mathrm{O}_{6}}$ & $\mathrm{ET}_{\mathrm{O}_{7}}$ \\
\hline $\begin{array}{l}4 \\
5 \\
6 \\
7 \\
8\end{array}$ & & $\begin{array}{l}0,4 \\
3,2 \\
4,3 \\
4,4 \\
4,2\end{array}$ & $\begin{array}{l}3,4 \\
3,5 \\
4,1 \\
3,6 \\
3,7\end{array}$ & $\begin{array}{l}3,5 \\
4,0 \\
5,9 \\
5,9 \\
4,7\end{array}$ & $\begin{array}{l}2,7 \\
2,9 \\
3,3 \\
3,2 \\
3,0\end{array}$ & $\begin{array}{l}2,7 \\
3,4 \\
3,5 \\
3,4 \\
3,3\end{array}$ & \\
\hline $\mathbf{M}$ & & 3,3 & 3,6 & 4,5 & 3,0 & 3,2 & 1,7 \\
\hline $\begin{array}{l}9 \\
10 \\
11 \\
12 \\
13\end{array}$ & & $\begin{array}{r}4,4 \\
4,4 \\
3,4 \\
4,0 \\
2,8\end{array}$ & $\begin{array}{l}4,5 \\
4,4 \\
3,4 \\
3,4 \\
3,3\end{array}$ & $\begin{array}{l}4,6 \\
4,6 \\
4,6 \\
4,7 \\
4,4\end{array}$ & $\begin{array}{l}2,9 \\
3,0 \\
2,8 \\
2,8 \\
2,8\end{array}$ & $\begin{array}{l}3,4 \\
3,4 \\
3,3 \\
3,2 \\
3,4\end{array}$ & \\
\hline M & & 3,8 & 3,8 & 4,6 & 2,9 & 3,4 & 1,9 \\
\hline $\begin{array}{l}19 \\
20 \\
21 \\
22 \\
23\end{array}$ & & $\begin{array}{c}2,6 \\
- \\
2,7 \\
2,9 \\
0,8\end{array}$ & $\begin{array}{l}2,8 \\
- \\
2,6 \\
3,2 \\
1,2\end{array}$ & $\begin{array}{l}4,4 \\
4,5 \\
4,7 \\
4,0 \\
1,9\end{array}$ & $\begin{array}{l}2,6 \\
2,5 \\
2,8 \\
2,7 \\
2,0\end{array}$ & $\begin{array}{l}3,0 \\
3,0 \\
3,4 \\
3,2 \\
2,1\end{array}$ & \\
\hline $\mathbf{M}$ & & 2,3 & 2,4 & 3,9 & 2,6 & 3,0 & 1,6 \\
\hline $\begin{array}{l}24 \\
25 \\
26 \\
27 \\
28\end{array}$ & & $\begin{array}{l}1,0 \\
2,7 \\
2,6 \\
1,0 \\
0,3\end{array}$ & $\begin{array}{l}2,1 \\
2,8 \\
3,3 \\
2,5 \\
1,2\end{array}$ & $\begin{array}{l}1,8 \\
3,2 \\
4,0 \\
2,7 \\
1,8\end{array}$ & $\begin{array}{l}1,8 \\
2 ; 8 \\
3 ; 3 \\
2 ; 3 \\
1,7\end{array}$ & $\begin{array}{l}2,2 \\
2,9 \\
3,4 \\
2,5 \\
2,0\end{array}$ & \\
\hline M & . & 1,5 & 2,4 & 2,6 & 2,4 & 2,6 & 2,9 \\
\hline $\begin{array}{c}29 \\
30 \\
01 / 05 \\
02 / 05 \\
03 / 05\end{array}$ & & $\begin{array}{l}1,7 \\
2,9 \\
2,5 \\
2,2 \\
2,2\end{array}$ & $\begin{array}{l}1,9 \\
3,1 \\
1,6 \\
2,3 \\
-\end{array}$ & $\begin{array}{l}1,8 \\
4,4 \\
3,8 \\
3,2 \\
3,3\end{array}$ & $\begin{array}{l}1,9 \\
4,7 \\
1,8 \\
2,0 \\
2,5\end{array}$ & $\begin{array}{l}2,1 \\
2,9 \\
2,4 \\
2,4 \\
2,7\end{array}$ & . \\
\hline$M$ & & 2,3 & 2,1 & 3,3 & 1,9 & 2,4 & 1,6 \\
\hline
\end{tabular}


71.

Quadro V - (Continuação)

Ma io

\begin{tabular}{|c|c|c|c|c|c|c|}
\hline DIAS & $\overline{E T}_{\mathrm{O}_{12}}$ & $\mathrm{ET}_{\mathrm{O}_{3}}$ & $\mathrm{ET}_{\mathrm{O}_{4}}$ & $\mathrm{ET}_{\mathrm{O}_{5}}$ & $\mathrm{ET}_{\mathrm{O}_{6}}$ & $\mathrm{ET}_{07}$ \\
\hline $\begin{array}{l}4 \\
5 \\
6 \\
7 \\
8\end{array}$ & $\begin{array}{l}2,3 \\
1,9 \\
2,5 \\
2,6 \\
2,4\end{array}$ & $\begin{array}{l}2,3 \\
2,1 \\
2,6 \\
2,5 \\
2,7\end{array}$ & $\begin{array}{l}2,0 \\
3,0 \\
3,8 \\
3,3 \\
3,1\end{array}$ & $\begin{array}{l}1,5 \\
1,8 \\
2,1 \\
2,0 \\
1,9\end{array}$ & $\begin{array}{l}1,8 \\
2,2 \\
2,5 \\
2,6 \\
2,5\end{array}$ & \\
\hline $\mathrm{M}$ & 2,3 & 2,5 & 2,9 & 1,9 & 2,3 & 1,7 \\
\hline $\begin{array}{r}9 \\
10 \\
11 \\
12 \\
13\end{array}$ & $\begin{array}{r}2,6 \\
3,6 \\
3,1 \\
2,3 \\
2,8\end{array}$ & $\begin{array}{l}2,9 \\
2,7 \\
2,7 \\
2,5 \\
2,6\end{array}$ & $\begin{array}{l}3,1 \\
3,9 \\
3,9 \\
3,3 \\
3,9\end{array}$ & $\begin{array}{l}1,4 \\
2,1 \\
2,1 \\
1,9 \\
2,0\end{array}$ & $\begin{array}{l}2,6 \\
2,8 \\
2,7 \\
2,6 \\
2,7\end{array}$ & \\
\hline $\mathbf{M}$ & 2,9 & 2,7 & 3,3 & 2,0 & 2,7 & 1,8 \\
\hline $\begin{array}{l}14 \\
15 \\
16 \\
17 \\
18\end{array}$ & $\begin{array}{l}2,9 \\
2,6 \\
2,0 \\
3,1 \\
3,2\end{array}$ & $\begin{array}{l}3,4 \\
2,5 \\
1,6 \\
2,7 \\
2,9\end{array}$ & $\begin{array}{l}2,7 \\
2,9 \\
1,8 \\
2,7 \\
3,0\end{array}$ & $\begin{array}{l}2,3 \\
1,9 \\
1,6 \\
2,2 \\
2,3\end{array}$ & $\begin{array}{l}3,2 \\
2,4 \\
2,1 \\
2,6 \\
3,0\end{array}$ & \\
\hline$M$ & 2,8 & 2,6 & 3,0 & 2,1 & 2,6 & 1,8 \\
\hline $\begin{array}{l}19 \\
20 \\
21 \\
22 \\
23\end{array}$ & $\begin{array}{l}2,1 \\
1,6 \\
1,6 \\
3,7 \\
2,7\end{array}$ & $\begin{array}{l}2,3 \\
2,1 \\
2,0 \\
3,0 \\
2,4\end{array}$ & $\begin{array}{l}2,8 \\
2,4 \\
2,7 \\
3,5 \\
3,0\end{array}$ & $\begin{array}{l}2,0 \\
1,9 \\
1,8 \\
2,0 \\
1,9\end{array}$ & $\begin{array}{l}2,4 \\
2,3 \\
2,3 \\
2,6 \\
2,4\end{array}$ & \\
\hline$M$ & 2,3 & 2,5 & 2,7 & 1,9 & 2,4 & 1,8 \\
\hline $\begin{array}{l}24 \\
25 \\
26 \\
27 \\
28\end{array}$ & $\begin{array}{l}3,1 \\
1,6 \\
3,0 \\
1,5 \\
2,3\end{array}$ & $\begin{array}{l}2,5 \\
2,6 \\
2,7 \\
2,1 \\
2,0\end{array}$ & $\begin{array}{l}3,0 \\
3,4 \\
4,6 \\
3,1 \\
2,2\end{array}$ & $\begin{array}{l}1,7 \\
1,8 \\
1,8 \\
1,9 \\
1,7\end{array}$ & $\begin{array}{l}2,4 \\
2,6 \\
2,6 \\
2,4 \\
2,1\end{array}$ & \\
\hline $\mathbf{M}$ & 2,3 & 2,3 & 3,1 & 1,8 & 2,4 & 1,2 \\
\hline $\begin{array}{c}29 \\
30 \\
31 \\
01 / 06 \\
02 / 06\end{array}$ & $\begin{array}{l}2,9 \\
2,8 \\
2,9 \\
2,2 \\
3,2\end{array}$ & $\begin{array}{l}2,4 \\
2,8 \\
2,5 \\
2,6 \\
3,4\end{array}$ & $\begin{array}{l}3,8 \\
3,7 \\
3,9 \\
2,4 \\
3,7\end{array}$ & $\begin{array}{l}1,9 \\
3,0 \\
1,9 \\
1,6 \\
2,1\end{array}$ & $\begin{array}{l}2,5 \\
2,8 \\
2,7 \\
2,3 \\
3,1\end{array}$ & \\
\hline $\mathbf{M}$ & 2,8 & 2,7 & 3,1 & 2,5 & 2,7 & 1,1 \\
\hline
\end{tabular}


Quadro V - (Continuação).

72.

Junho

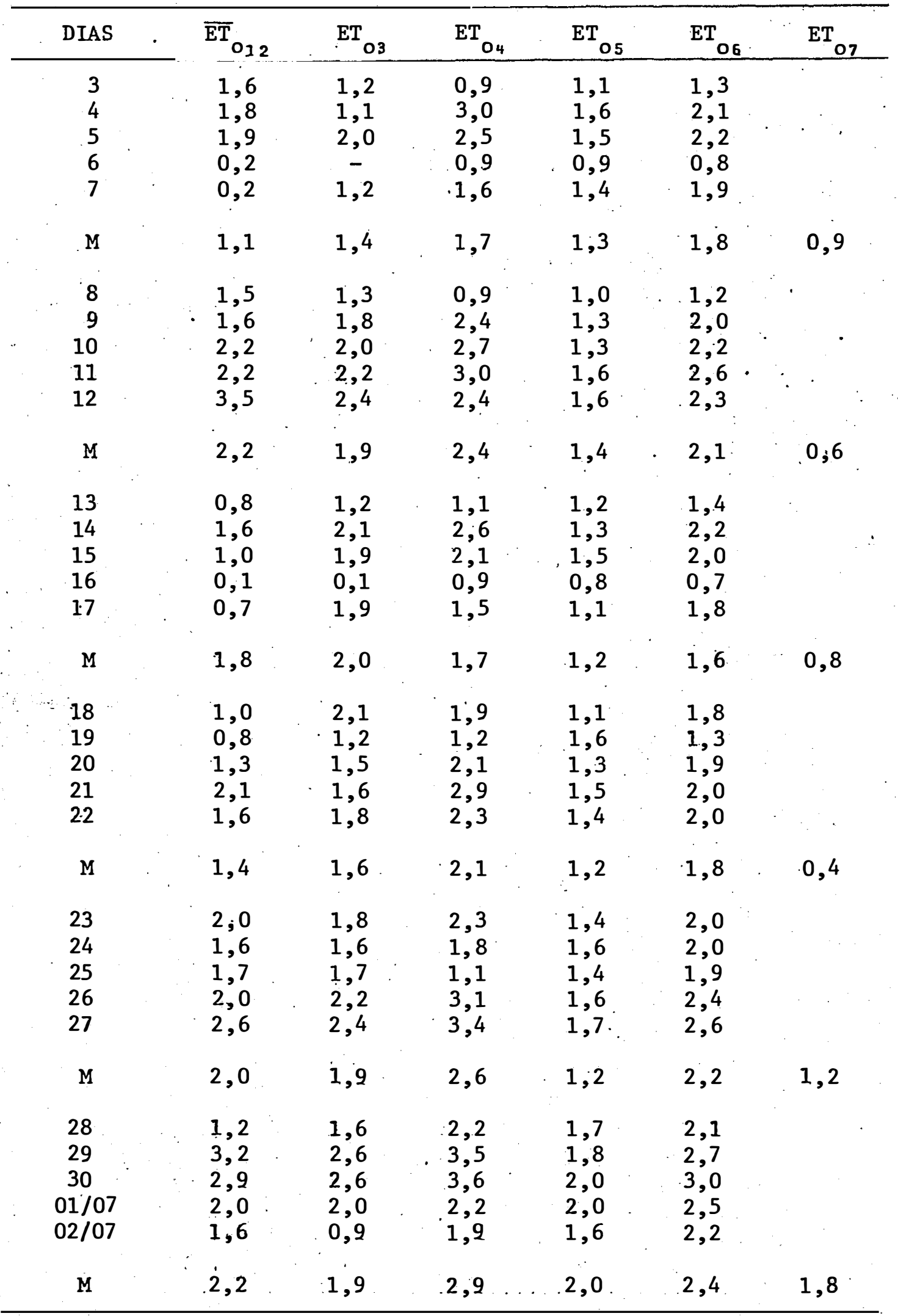


73.

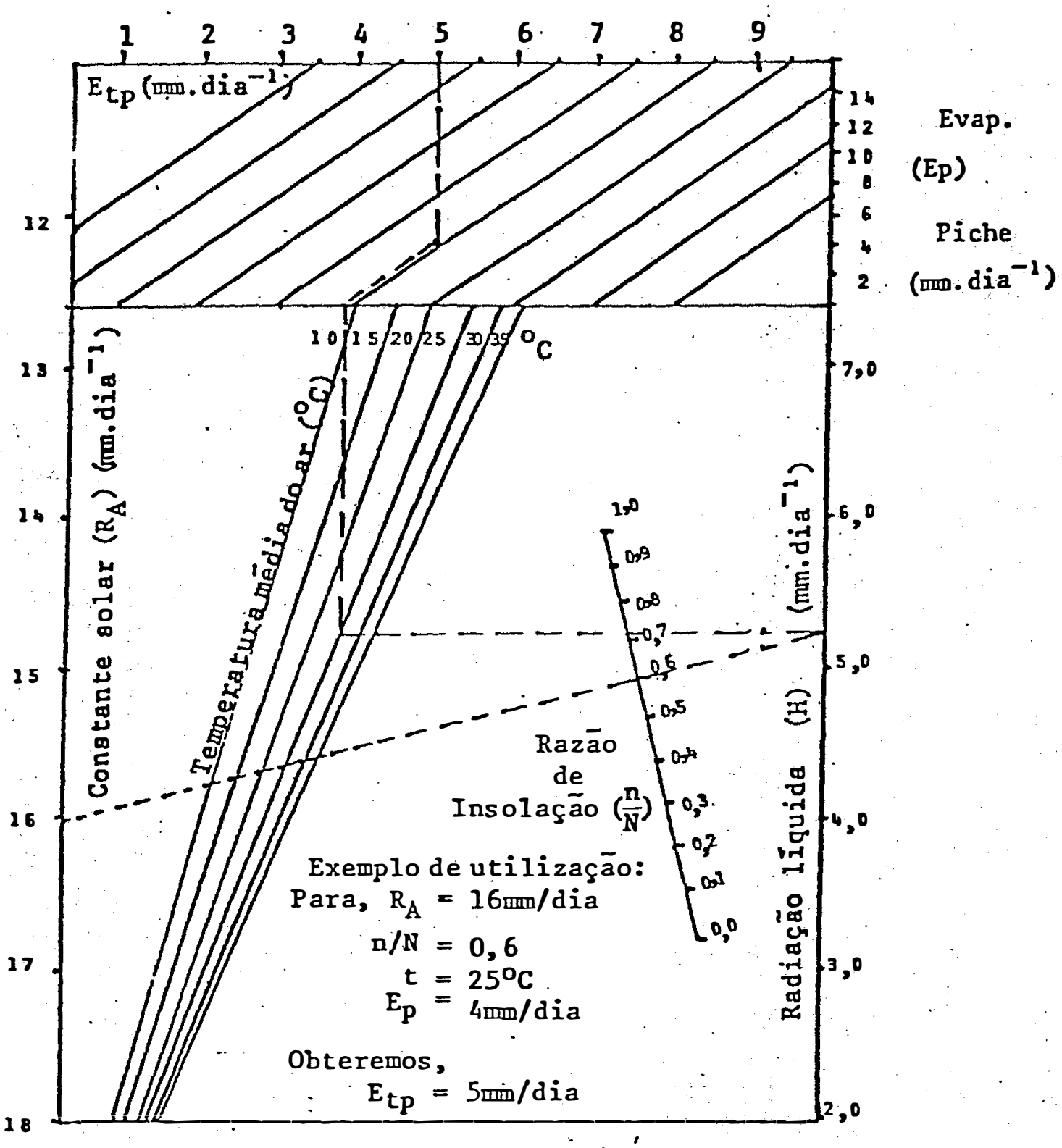

Figura 1. Nomograma para cálculo da Evapotranspiração Potencial pelo método de Penman simplificado Utilizável no período outubro a março (pri mavera-veräo) entre latitudes $20^{\circ}$ a $25^{\circ}$ Sul [VILLA NOVA e OMETTO (1981)] 
74.

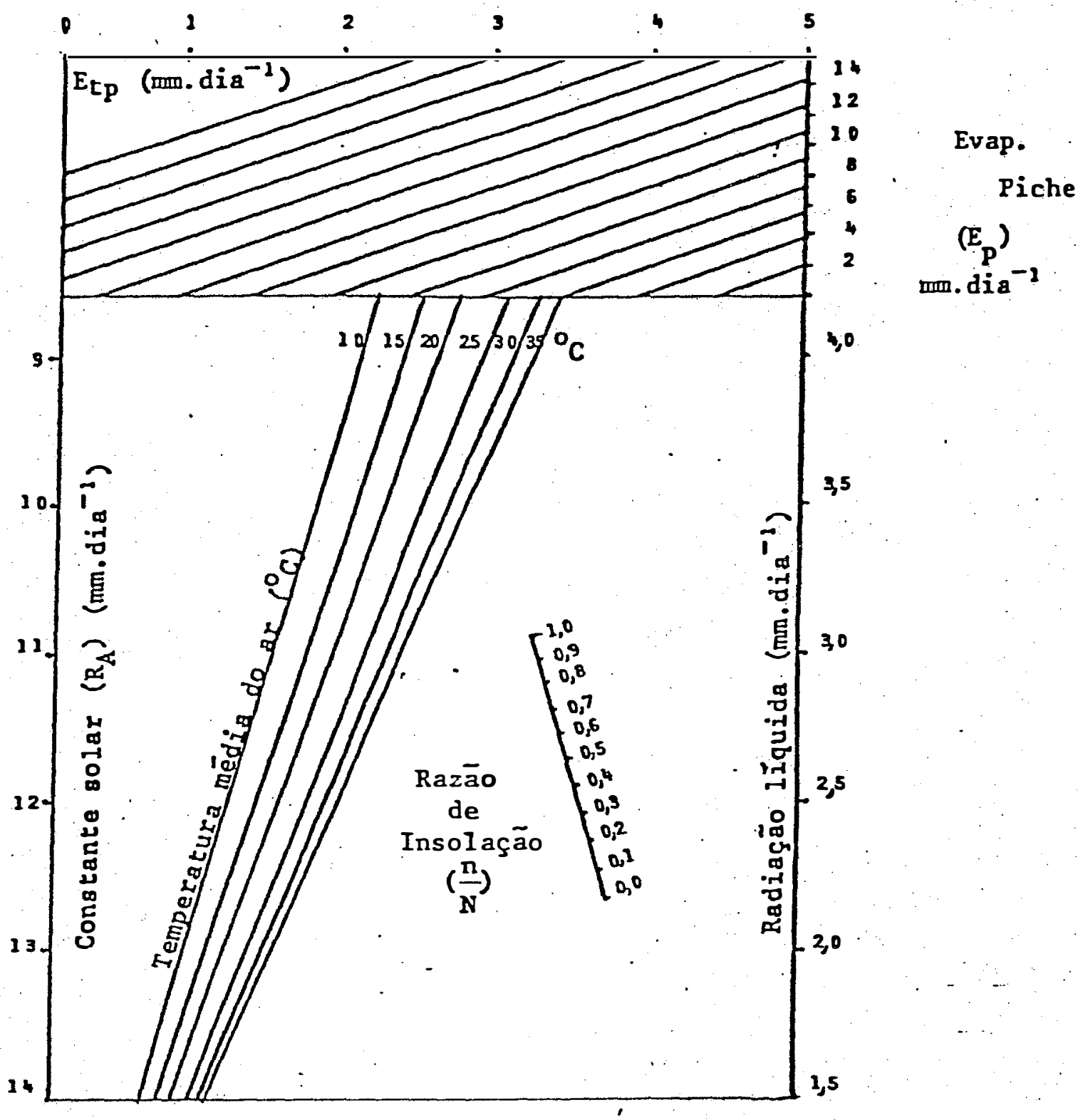

Figura 2. Nomograma para cálculo da Evapotranspiração Potencial pelo método de Penman simplificado -Utilizável no período abril a setembro (ou tono - inverno) entre latitudes $20^{\circ}$ a $25^{\circ} \mathrm{Sul}$ [VILLA NOVA e OMETTO (1981)] 

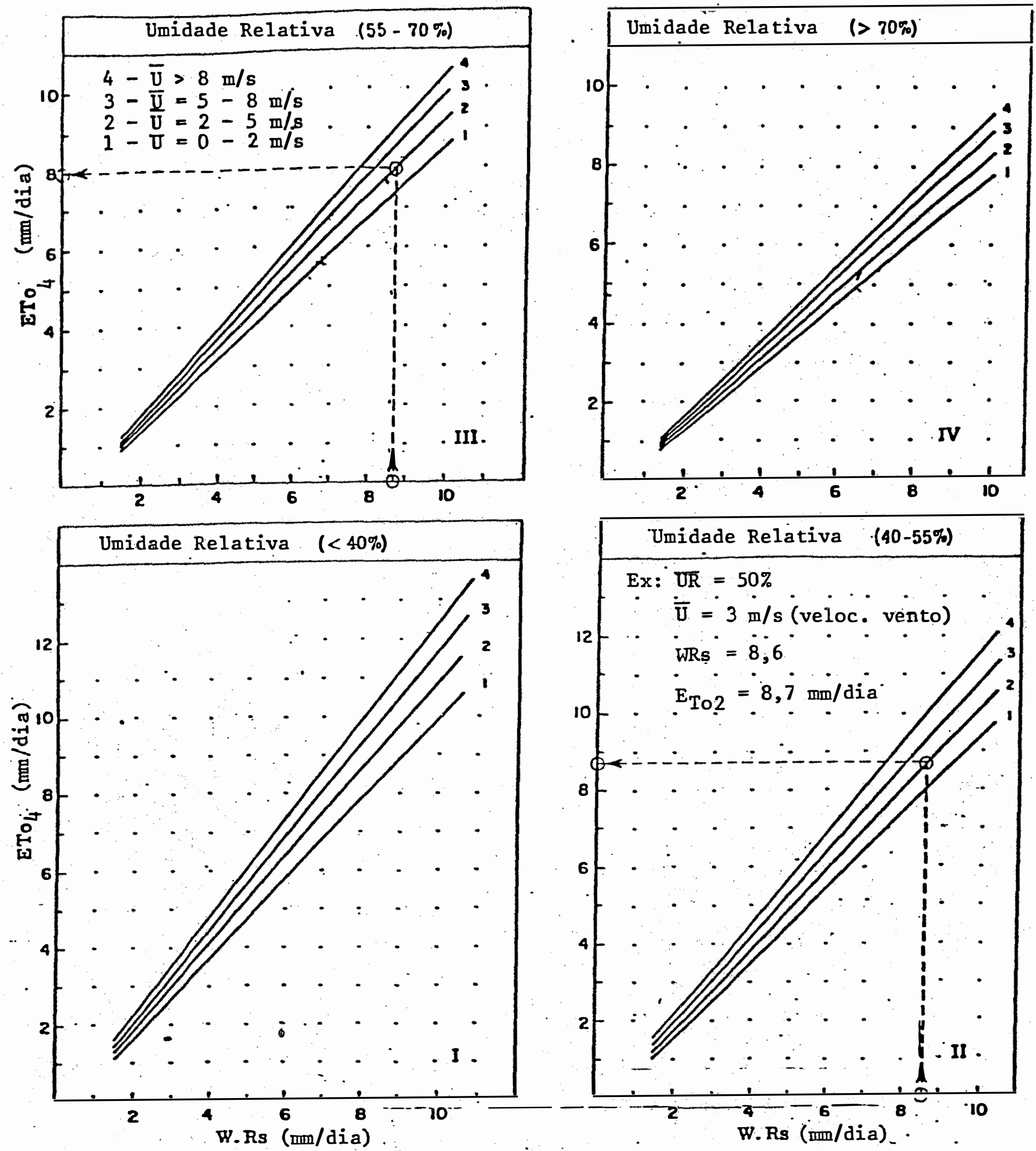

Figura 3. Estimativa de ETơ em função do produto wRs para diferentes níveis de Umidade relativa (\%) e velocidade média diurna de vento (m/s). 